OPEN ACCESS

Edited by:

Nina Rønsted,

National Tropical Botanical Garden,

United States

Reviewed by:

Martin Röser,

Martin Luther University

of Halle-Wittenberg, Germany

Josef Greimler,

University of Vienna, Austria

Guillaume Besnard,

UMR 5174 Evolution et Diversite

Biologique (EDB), France

${ }^{*}$ Correspondence:

Pilar Catalán

pcatalan@unizar.es

Specialty section:

This article was submitted to Plant Systematics and Evolution,

a section of the journal

Frontiers in Plant Science

Received: 31 January 2020 Accepted: 22 May 2020

Published: 26 June 2020

Citation:

Moreno-Aguilar MF, Arnelas I, Sánchez-Rodríguez A, Viruel $J$ and Catalán P (2020) Museomics Unveil the Phylogeny and Biogeography of the Neglected Juan Fernandez

Archipelago Megalachne and Podophorus Endemic Grasses and Their Connection With Relict

Pampean-Ventanian Fescues.

Front. Plant Sci. 11:819.

doi: 10.3389/fp/s.2020.00819

\section{Museomics Unveil the Phylogeny and Biogeography of the Neglected Juan Fernandez Archipelago Megalachne and Podophorus Endemic Grasses and Their Connection With Relict Pampean-Ventanian Fescues}

\author{
María Fernanda Moreno-Aguilar ${ }^{1}$, Itziar Arnelas², Aminael Sánchez-Rodríguez², \\ Juan Viruel ${ }^{3}$ and Pilar Catalán ${ }^{1,4,5 *}$
}

${ }^{1}$ Escuela Politécnica Superior de Huesca, Universidad de Zaragoza, Huesca, Spain, ${ }^{2}$ Departamento de Ciencias Biológicas, Universidad Técnica Particular de Loja, Loja, Ecuador, ${ }^{3}$ Royal Botanic Gardens, Kew, Richmond, United Kingdom, ${ }^{4}$ Grupo de Bioquímica, Biofísica y Biología Computacional (BIFI, UNIZAR), Unidad Asociada al CSIC, Zaragoza, Spain, ${ }^{5}$ Department of Botany, Institute of Biology, Tomsk State University, Tomsk, Russia

Oceanic islands constitute natural laboratories to study plant speciation and biogeographic patterns of island endemics. Juan Fernandez is a southern Pacific archipelago consisting of three small oceanic islands located $600-700 \mathrm{~km}$ west of the Chilean coastline. Exposed to current cold seasonal oceanic climate, these 5.8-1 Ma old islands harbor a remarkable endemic flora. All known Fernandezian endemic grass species belong to two genera, Megalachne and Podophorus, of uncertain taxonomic adscription. Classical and modern classifications have placed them either in Bromeae (Bromus), Duthieinae, Aveneae/Poeae, or Loliinae (fine-leaved Festuca); however, none of them have clarified their evolutionary relationships with respect to their closest Festuca relatives. Megalachne includes four species, which are endemic to Masatierra (Robinson Crusoe island) (M. berteroniana and M. robinsoniana) and to Masafuera (Alejandro Selkirk island) (M. masafuerana and M. dantonii). The monotypic Podophorus bromoides is a rare endemic species to Masatierra which is only known from its type locality and is currently considered extinct. We have used museomic approaches to uncover the challenging evolutionary history of these endemic grasses and to infer the divergence and dispersal patterns from their ancestors. Genome skimming data were produced from herbarium samples of $M$. berteroniana and $M$. masafuerana, and the 164 years old type specimen of $P$. bromoides, as well as for a collection of 33 species representing the main broad- and fine-leaved Lolinae lineages. Pairedend reads were successfully mapped to plastomes and nuclear ribosomal cistrons of reference Festuca species and used to reconstruct phylogenetic trees. Filtered ITS and trnTLF sequences from these genomes were further combined with our large Loliinae data sets for accurate biogeographic reconstruction. Nuclear and plastome data recovered a strongly supported fine-leaved Fernandezian clade where Podophorus was 
resolved as sister to Megalachne. Bayesian divergence dating and dispersal-extinctioncladogenesis range evolution analyses estimated the split of the Fernandezian clade from its ancestral southern American Pampas-Ventanian Loliinae lineage in the MiocenePliocene transition, following a long distance dispersal from the continent to the uplifted volcanic palaeo-island of Santa Clara-Masatierra. Consecutive Pliocene-Pleistocene splits and a Masatierra-to-Masafuera dispersal paved the way for in situ speciation of Podophorus and Megalachne taxa.

Keywords: ancestral range reconstruction, endemic Loliinae grasses, Fernandezian clade, genome skimming, phylogenomics, taxonomically neglected species

\section{INTRODUCTION}

Genomic data are increasingly called upon to elucidate evolutionary and taxonomic challenges posed by several cryptic or ambiguously related organisms, which could not be resolved using traditional approaches, such as morphometrics or standard molecular methods (Harrison and Kidner, 2011; Straub et al., 2012; Carter et al., 2020; Larridon et al., 2020). The advent of the high-throughput sequencing (HTS) methods have outpaced classical molecular barcoding and phylogenetic procedures based on few molecular markers that have served to build phylogenies with constrained resolution limits (Diaz-Perez et al., 2018; Sancho et al., 2018). While the results obtained from the genomic-based approaches are overall congruent with previous findings based on reduced sets of genes and genetic markers (Saarela et al., 2018), the thoroughly dissection of genomes have untapped large sets of taxonomically informative gene copy variants or single nucleotide polymorphism (SNPs) and have allowed the reconstruction of better resolved and more strongly supported phylogenies (Soltis et al., 2018). These new metadata have facilitated the identification of previously neglected cryptic taxa (Spriggs et al., 2019) and the construction of more robust phylogenetic trees where the evolutionary positions of previously unknown, doubtful, or ambiguous lineages have been elucidated in some cases (Leebens-Mack et al., 2019; Li et al., 2019).

The application of HTS methods to the analysis of museum collections, defined as museomics, has revolutionized the study of the organismic diversity (Besnard et al., 2014; Nevill et al., 2020). Plant herbarium specimens were occasionally used in traditional phylogenetic and population genetic studies due to the poor preservation of the specimens or their low quality DNA. Herbarium specimens have been progressively incorporated to taxonomic and evolutionary studies using HTS methods thanks to the simultaneous generation of a large quantity of sequences for the different genomes present in an organism (Straub et al., 2012; Besnard et al., 2014). Among the HTS approaches used with both herbarium and fresh collections, genome skimming (Dodsworth, 2015; Richter et al., 2015) has been successfully applied to reconstruct DNA genomes and regions that exist in multiple copies, such as plastomes, mitomes and the nuclear ribosomal cistron, and even some nuclear single copy genes (Besnard et al., 2014). Among other advances, museomics has untapped the placement of recently extinct taxa in phylogenies (Sebastian et al., 2010; Welch et al., 2016; Zedane et al., 2016;
Silva et al., 2017). Thus, the combined use of current and extinct plant species samples, and of herbarium and recently collected samples allows to uncover largely sampled phylogenetic trees of plant lineages (Malakasi et al., 2019).

Oceanic archipelagos have been recognized as hotspots of diversity and natural laboratories for long distance colonization and plant speciation events (Triantis et al., 2016). Juan Fernandez is one of the smallest oceanic archipelagos. It consists of three small islands located in the southern Pacific, $580-730 \mathrm{~km}$ offshore of the western Chilean coast [Masatierra or Robinson Crusoe (47.94 km² , 0-915 masl), Masafuera or Alejandro Selkirk (49.52 $\left.\mathrm{km}^{2}, 0-1,319 \mathrm{masl}\right)$, and Santa Clara $\left(2.21 \mathrm{~km}^{2}, 0-\right.$ 350 masl)] (Stuessy et al., 1992, 2017). The two main islands have similar sizes but differ in plant communities and diverse grassland extensions due to their different ages and erosional patterns (Greimler et al., 2017), and are separated each other by $181 \mathrm{~km}$ (Figure 1). The current Fernandezian volcanic islands are relatively young (Stuessy et al., 1984). Despite its total small area $\left(100.2 \mathrm{~km}^{2}\right)$, the archipelago harbors one of the richest endemic floras (60\% vascular species, $11 \%$ genera, 1 paleoherb family; Stuessy et al., 1992). Floristic studies indicate that 55 grass species grow in Juan Fernandez archipelago; most of them are invasive taxa except five endemic species that belong to the Fernandezian Megalachne Steud. and Podophorus Phil. genera (Baeza et al., 2007; Peña et al., 2017; PenneckampFurniel and Villegas, 2019). Megalachne and the monotypic genus Podophorus have been historically assigned to different temperate grass tribes. Megalachne was originally described by Steudel in 1854 as close to Bromus (it was also described as Pathantera by Philippi in 1856), though they differ in the number and disposition of the stigmas (three apical in Megalachne, two subapical in Bromus) and the shape of the glume apex (aristulate in Megalachne, mutique in Bromus; Hackel, 1887). However, Pilger in 1920 and Skottsberg in 1922 transferred, respectively, Megalachne and Pathantera to Bromus, based on the sharing of laterally compressed spikelets and keeled lemmas, such as those in Bromus sect. Ceratochloa (Peña et al., 2017) thus classifying them within tribe Bromeae. In 1954, Pilger recognized Megalachne as a separate genus from Bromus (Peña et al., 2017); Tateoka (1962) using evidences from the morphology and apical hairiness of the ovary, apical emergence of stigmas, and type of starch grains and serology, suggested the proximity of Megalachne to Festuca, thus attributing it to tribe Poeae (subtribe Loliinae). The taxonomic adscription of Megalachne and Podophorus to 


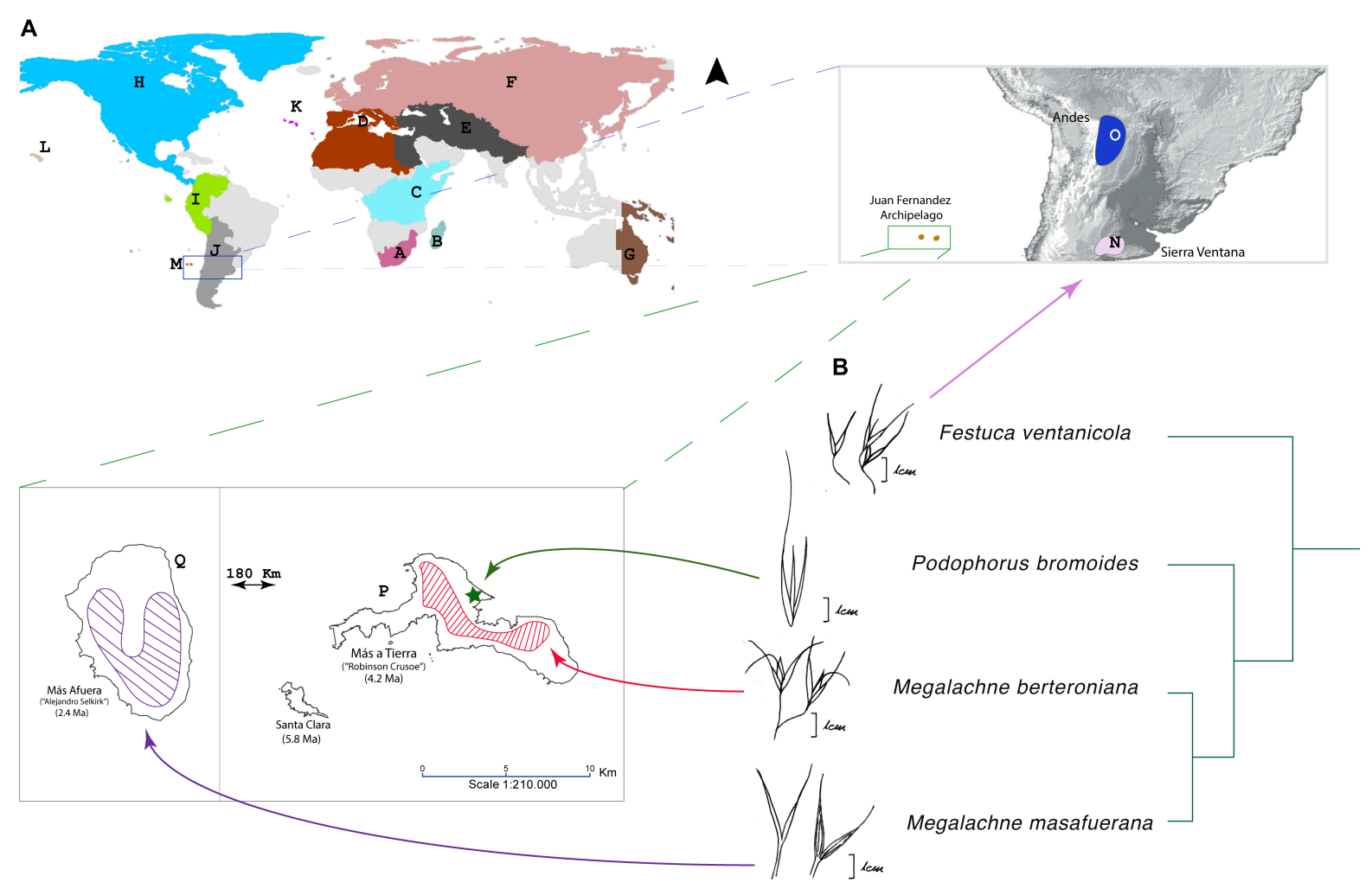

FIGURE 1 | (A) Distribution map of the Juan Fernandez archipelago Megalachne and Podophorus species included in this study [M. berteroniana and M. masafuerana distributions have been obtained from Peña et al. (2017) and Penneckamp-Furniel and Villegas (2019); P. bromoides is tentatively mapped in the Cumberley bay of Masatierra; cf. Baeza et al. (2007)] and of the Pampean-Ventanian Festuca ventanicola, showing the world and the American-Vulpia-Pampas Operational areas (OAs) used in the biogeographical analyses of Loliinae. OAs: Loliinae DEC model: A - South Africa; B - Madagascar and Mascarenes; C - Tropical Africa; D - Mediterranean; E - Irano-Turanian-Himalayan region; F - Eurasia (Eurosiberian region); G - Australasia (New Zealand, south-western Australia, Papua-New Guinea); H - North and Central America; I - Northern Andes; J - Southern Andes and Southern South America; K - Macaronesia; L - Hawaii; M - Juan Fernández; American-Vulpia-Pampas DEC model: H - North and Central America; N - Pampas-Ventania; O - Andes; P - Masatierra; Q - Masafuera. (B) Phylogenetic ITS-TLF subtree showing the relationships of the Fernandezian Podophorus bromoides, Megalachne berteroniana, and M. masafuerana grasses and its close relative Festuca ventanicola; drawns of the floral "vulpioid" phenotype are shown for each species.

tribe Poeae was accepted in most grass classifications though Soreng et al. (2003) assigned them initially to tribe Stipeae subtribe Duthieinae based on the overall habit resemblance. Nonetheless, the comprehensive morphological and molecular study of the newly delimited tribe Duthieeae of Schneider et al. (2011) demonstrated, using ITS sequences, that Megalachne and Podophorus were not part of this early diverging pooid lineage, and suggested that they likely belonged to the Aveneae/Poeae complex. In recent studies, phylogenetic analyses conducted by Schneider et al. (2012) and Tkach et al. (2020) using, respectively, nuclear ITS and plastid mat K sequences and nuclear ITS and ETS and plastid matK, trnK, and trnLF sequences corroborated it, showing that Megalachne was nested within the fine-leaved Loliinae clade.

Megalachne and Podophorus differentiate from each other in the number of florets per spikelet [3-6 in Megalachne, 1$(+1$ sterile) in Podophorus), the type of lemma (keeled vs. rounded], the length of the glumes (equal vs. shorter than anthecium) and the prolongation of the rachilla apex (shorther vs. equal than anthecium; Baeza et al., 2007; Kellogg, 2015;
Peña et al., 2017). Megalachne consisted until recently of two species, M. berteroniana Steud. and M. masafuerana (Skottsb. \& Pilg. ex. Pilg.) Matthei, endemic to the Masatierra and Masafuera islands, respectively (Baeza et al., 2007). Both species grow in coastal and mountain cliffs in their respective islands (Danton et al., 2006). Recent morphological studies have identified two new species, $M$. robinsoniana C. Peña, endemic to Masatierra (Peña et al., 2017), and M. dantonii Penneck. \& Gl. Rojas, endemic to Masafuera (Penneckamp-Furniel and Villegas, 2019). The four Megalachne species differ in the lengths of the lemma and glume awns and the number of florets per spikelet (Peña et al., 2017; Penneckamp-Furniel and Villegas, 2019). The systematic and evolutionary fate of Podophorus is more enigmatic. Its single species $P$. bromoides Phil. is only known from its type specimens, collected in Masatierra and described by Philippi in 1856, and is currently considered to be extinct (Baeza et al., 2007).

Loliinae is one of the largest subtribes of the temperate pooid grasses and contains pasture and forage species of high ecological and economic importance. Its largest genus Festuca 
is formed by $\sim 600$ worldwide distributed species inhabiting cool seasonal regions of both hemispheres and high tropical mountains (Catalan, 2006). Molecular phylogenetic studies have shown that Festuca is largely paraphyletic (Catalan et al., 2007; Inda et al., 2008; Minaya et al., 2017). Recent studies, based on the Schneider et al. $(2011,2012)$ ITS and matK data and previous morphological findings, reclassified Megalachne and Podophorus within subtribe Loliinae (Soreng et al., 2015, 2017), however, they did not identify the closest relatives of these Fernandezian grasses. The phylogenetic relationships obtained by previous authors for the three studied Megalachne and Podophorus taxa were also taxonomically incongruent, showing a closer relationship of $M$. berteroniana to $P$. bromoides than to its congener M. masafuerana (Schneider et al., 2011).

Here we have used a museomic approach based on genome skimming data to uncover the phylogenetic and biogeographical history of the neglected Fernandezian Megalachne and Podophorus grasses. The aims of our study were to (i) infer the phylogeny of Megalachne and Podophorus within a large sample representation of Lolinae lineages; (ii) identify the closest relatives of the Fernandezian grasses; (iii) reconstruct the relationships among the Megalachne and Podophorus taxa; (iv) estimate divergence times of the Fernandezian lineages; and (v) infer the colonization patterns and speciation events of the ancestors of Megalachne and Podophorus in the Juan Fernandez islands.

\section{MATERIALS AND METHODS}

\section{Sampling}

Representative samples of Megalachne, Podophorus, and other Loliinae genera were included in the study (Figure 1 and Table 1). Herbarium samples of Megalachne berteroniana and M. masafuerana provided by the Oregon State University Herbarium (OSC11751 and OSC9150 collections; Table 1) were used to isolate high quality and quantity DNA for genome sequencing and downstream evolutionary analyses. A herbarium sample of $M$. robinsoniana provided by the Concepción University Herbarium (CONC40598 collection) failed to generate good quality DNA for the study. The recently described M. dantonii species (Penneckamp-Furniel and Villegas, 2019) could not be included in our study. A 164 years old sample of the currently considered extinct Podophorus bromoides Phil., only known from its three type specimens, was provided by the Royal Botanic Gardens Kew's Herbarium (Philippi 1861, isotype collection; Table $\mathbf{1})^{1}$ and was successfully used for genome skimming sequencing and downstream analysis. In our aim to identify the closest relatives of the Fernandezian Megalachne and Podophorus grasses, DNA was also isolated from 33 Loliinae samples (Table 1) representing all the known broad-leaved, intermediate, and fine-leaved Loliinae lineages (Inda et al., 2008; Minaya et al., 2017) and used for genome skimming sequencing and phylogenomic analyses. Some of these samples were collected from poorly explored geographical areas,

\footnotetext{
${ }^{1}$ https://apps.kew.org/herbcat/getImage.do?imageBarcode=K000433684
}

including four new Festuca samples from South America, the putative region of origin of the ancestors of Megalachne and Podophorus (Stuessy et al., 2017) and two from Tropical Africa and South Africa. In addition, two new Loliinae samples from South America and one sample from South Africa not studied before (Table 1) were sequenced for the nuclear ITS (ITS15.8S-ITS2) and the plastid trnTL (trnT-trnL intergenic spacer) and $\operatorname{trn} \mathrm{LF}$ (trn A-Leu, $\operatorname{trn} \mathrm{L}-\operatorname{trn} \mathrm{F}$ intergenic spacer, $\operatorname{trn} \mathrm{A}-\mathrm{Phe})$ loci, together with 97 samples from a wide-sampling of all currently known Loliinae lineages (Inda et al., 2008; Minaya et al., 2017). Although species of Megalachne and Podophorus and other fine-leaved Loliinae genera have been synonymized to Festuca, and those of broad-leaved Loliinae to different festucoid genera in recent studies (Soreng et al., 2017; Tkach et al., 2020), we follow the Festuca sensu lato classification of Catalan et al. (2007) which is based on an evolutionary systematic criterion that is nomenclaturally conservative and maintains a paraphyletic Festuca (with subgenera and sections) and other traditionally recognized genera until more complete phylogenetic studies of Loliinae are conducted. We have selected this scenario because of present uncertainties about the phylogeny of several Loliinae lineages and taxonomic and nomenclatural instability of the Festuca sensu stricto (i.e., fineleaved Loliinae lineages) classification, that would leave some broad-leaved Loliinae lineages without name or with unclear adscription (e.g., some broad-leaved "Festuca"). It could be possible, however, that genera phylogenetically embedded within the large Loliinae clade or its fine-leaved subclade would be subordinated to Festuca, once all or most of the Loliinae taxa are phylogenetically analyzed and consistent synapomorphies are defined. At this respect, nomenclatural combinations have been proposed for the fine-leaved Megalachne (Festuca megalachna Röser \& Tkach; F. masafuerana (Skottsb. \& Pilg. ex Pilg.) Röser \& Tkach; F. robinsoniana (C.M.Peña) Röser \& Tkach; F. dolichathera Röser \& Tkach) and Podophorus (F. masatierrae Röser \& Tkach) species synonymized to Festuca (Tkach et al., 2020). Sixteen additional species were added as outgroups to provide reliable fossil calibration points for molecular dating (Supplementary Table S1).

\section{DNA Extraction and Sequencing}

The 36 samples used in this study were obtained from herbarium specimens (AARHUS, K, MO, US, OS, CONC, HUTPL, University of Zaragoza), silica gel dried leaf tissues collected in field trips, and fresh leaves collected from plants growing in the Universidad de Zaragoza - Escuela Politécnica Superior de Huesca common garden (Table 1 and Supplementary Table S1). Total DNA from fresh and silica gel dried samples was isolated following the DNeasy Plant Mini kit (Qiagen, Valencia, CA, United States) protocol using 20-30 mg of dry leaf tissue or $20 \mathrm{mg}$ of fresh tissue ground to powder with liquid nitrogen. Total DNA from herbarium samples was extracted using a modified CTAB protocol (Doyle and Doyle, 1987) using $\sim 20 \mathrm{mg}$ of tissue. DNA concentration was quantified with a Qubit fluorometer (Invitrogen by Life Technologies, Carlsbad, California, United States) and DNA quality was evaluated with Biodrop (Harvard Bioscience). The integrity of the DNA was 
TABLE 1 | List of taxa included in the phylogenomic study of the Fernandezian and other Lolinae grasses.

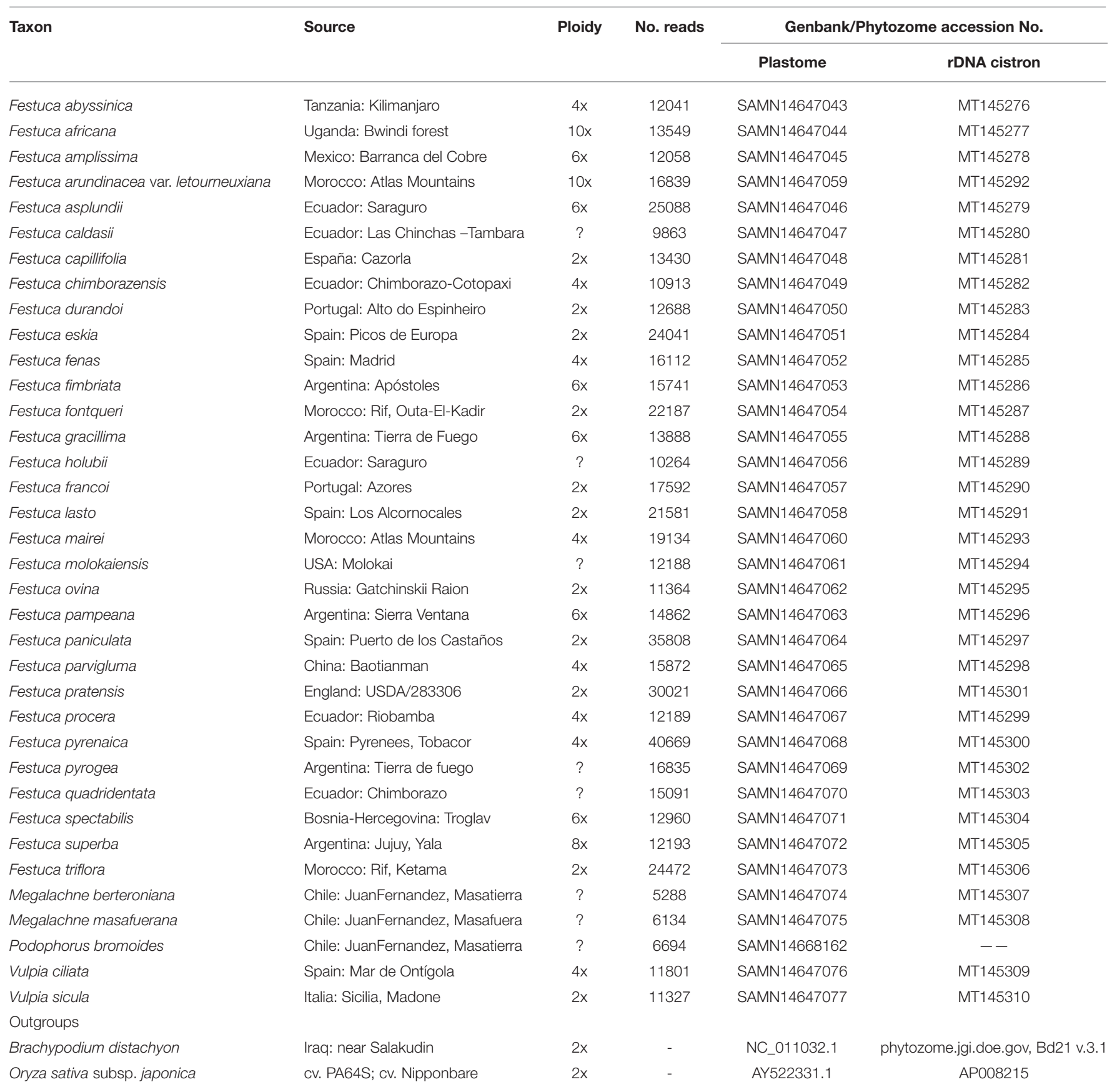

further checked in a $1 \%$ agarose gel. Overall the qualities and quantities of the DNAs were appropriate for genome skimming $(\sim 5 \mu \mathrm{g}, 50 \mathrm{ng} / \mu \mathrm{l})$, except that of $P$. bromoides, which had $<1 \mathrm{ng} / \mu \mathrm{l}$.

DNAs obtained from three Megalachne and Podophorus samples plus 33 Loliinae samples were used to construct a genomic library for shotgun sequencing using Illumina technology. The library from freshly and herbarium collected materials DNAs was prepared with KAPA Hyper Prep Kit for PCR-free workflows (Roche Kapa Biociences) with some minor modifications. In brief, $1.0 \mu \mathrm{g}$ of genomic DNA was sheared in a Covaris ${ }^{\mathrm{TM}}$ E220 focused-ultrasonicator into Covaris microTUBE AFA Fiber Pre-Slit Snap-Cap tubes with the following parameters: sample volume $55 \mu \mathrm{l}$, duty cycle $15 \%$, intensity 450 , cycles/burst 200, time $100 \mathrm{~s}$, temperature $4^{\circ} \mathrm{C}$, in order to reach the fragment sizes of $\sim 200-400 \mathrm{bp}$. The sheared DNA was end-repaired, adenylated and ligated to IDT adaptors with unique dual-matched indexes (Integrated DNA Technologies) for paired end sequencing. The adaptormodified end library was size selected and purified with AMPure 
XP beads (Agencourt, Beckman Coulter) in order to eliminate non-ligated adapters and adapter dimers. Final library size was confirmed on an Agilent 2100 Bioanalyzer with the DNA 7500 assay. The Podophorus bromoides library yielded $13 \mathrm{ng} / \mu \mathrm{l}$ and two normally distributed fragment size distributions of 200 and 500 bp. The PCR free library was quantified by Library Quantification Kit for Illumina Platforms (Roche Kapa Biosystems). The library was multiplexed with other libraries and the pool of libraries was then partly sequenced on a HiSeq4000 and partly on a HiSeq 2500 (TruSeq SBS Kit v4, Illumina, Inc) in paired-end mode $(2 \times 100 \mathrm{bp})$ in the Centro Nacional de Análisis Genómicos (CNAG, Barcelona). Primary data analysis, image analysis, base calling and quality scoring of the run were processed using the manufacturer's software Real Time Analysis (RTA 2.7.7) for HiSeq4000, and RTA1.18.66.3 when using HiSeq2500, followed by generation of FASTQ sequence files.

Additionally, four Loliinae samples (Supplementary Table S1) were used for Sanger sequencing of the nuclear ribosomal ITS locus and the plastid $\operatorname{trn} \mathrm{LF}$ and $\operatorname{trnTL}$ loci using the primers and procedures indicated in Inda et al. (2008) in Macrogen and were added to the 97 Loliinae data set obtained from previous studies (Inda et al., 2008; Minaya et al., 2017).

\section{DNA Sequence Data Assembling and Multiple Sequence Alignments}

Illumina paired-end (PE) reads of the Fernandezian and other Loliinae samples were checked using FASTQC ${ }^{2}$ and the adapters and low quality sequences were trimmed using TRIMMOMATIC (Bolger et al., 2014) at the CNAG. Plastome assembly was performed with Novoplasty v.2.7.1 (Dierckxsens et al., 2017) using the published plastomes of Festuca ovina (JX871940.1) for fine-leaved taxa and of $F$. pratensis (JX871941) for broadleaved taxa (Hand et al., 2013) as reference, and the following parameters: k-mer: 27 or 39, insert size: $\sim 300 \mathrm{bp}$, genome range: 120,000-220,000 bp, and PE reads: $101 \mathrm{bp}$. Assembled plastomes were aligned using MAFFT v.7.031b (Katoh and Standley, 2013) followed by visual inspection using Geneious R11 $1^{3}$. Because Novoplasty failed to assemble the whole plastome of $P$. bromoides due to the low number and quality of total PE reads, we used a Geneious mapping and readmerging strategy to map its reads to three phylogenetically close plastomes (Megalachne berteroniana, M. masafuerana, Festuca pampeana).

For the assembly of the nuclear ribosomal cistron we used a two-step read mapping and merging approach. Due to the lack of any published Loliinae rDNA cistron, we employed the Brachypodium distachyon $\mathrm{rDNA}$ cistron (reference genome $\mathrm{Bd} 21$, Vogel et al., 2010) ${ }^{4}$ as reference and mapped to it the PE reads of the studied Loliinae taxa. Readmerging allowed us to align reads and their reverse complements to create a single consensus read. This step also allowed improving the sequence quality of overlapping parts. In cases of non-overlapping PE reads, the reads were used independently. The integrity of the cistron locus was examined visually for read mappings using Geneious R11.

\footnotetext{
${ }^{2} \mathrm{http} / / /$ www.bioinformatics.babraham.ac.uk/projects/fastqc/

${ }^{3} \mathrm{https} / / / \mathrm{www} . g e n e i o u s . c o m$

${ }^{4}$ http://phytozome.jgi.doe.gov, v3.1Phytozome
}

Forward and reverse ITS, trnLF, and trnTL Sanger sequences were checked, corrected and merged using Sequencher v. 5.4.6 (Gene Codes Corporation, Ann Arbor, MI, United States) ${ }^{5}$. Each data set was aligned separately, visually inspected using Geneious R11 and manually corrected if necessary. The assembly of the P. bromoides $\operatorname{trn\mathrm {LF}}$ and $\operatorname{trn\mathrm {TL}}$ loci was done through several read mapping iterations with Geneious using as reference the closest $M$. berteroniana, M. masafuerana, $F$. ventanicola and F. pampeana trnLF and trnTL sequences.

A multiple sequence alignment (MSA) of 35 newly assembled Megalachne and Loliinae plastomes with Oryza sativa (AY522331.1; Genbank) and Brachypodium distachyon (NC_011032.1; Genbank) outgroups was performed with MAFFT v.7.215 (Katoh and Standley, 2013). The length of this full Loliinae plastome MSA without Podophorus was 146,172 bp length. The short $P$. bromoides consensus plastid sequence was subsequently aligned to the Loliinae full plastome MSA in Geneious R11. The multiple plastome alignment was filtered to remove poorly aligned regions and missing data in P. bromoides and other taxa through the automated option of trimAl v.1.2rev59 (Capella-Gutiérrez et al., 2009). The length of the filtered Loliinae plastome MSA with Podophorus was 55,872 bp length. A nuclear MSA of 35 newly assembled Megalachne and Loliinae rDNA cistrons and of Oryza sativa (AP008215; Genbank) and Brachypodium distachyon (Bd21; Phytozome) outgroups was also conducted with Geneious R11, rendering a 6,455 bp alignment. Independent MSAs were also produced for the ITS, $\operatorname{trnLF}$, and trnTL loci of 135 Loliinae species and 16 outgroups, which included the Megalachne and Podophorus samples in Geneious R11. The trnLF and trnTL plastid loci were combined into a single plastid TLF MSA; separate phylogenetic analyses of the two loci gave congruent topologies with that recovered for the concatenated TLF haploid data matrix and only results from the latter analysis will be explained further. The nuclear ITS and the plastid TLF data set were further combined into a ITS-TLF MSA after obtaining congruence results from contrasted topological tests.

\section{Phylogenetic Reconstruction and Divergence Time Analysis}

Maximum likelihood phylogenetic analysis of the plastome (full and reduced), the rDNA cistron, and the independent and combined ITS, and TLF data sets were conducted with IQTREE (Nguyen et al., 2015) imposing the best-fit nucleotide substitution model to each separate data set that was automatically selected by the ModelFinder option of the program (Kalyaanamoorthy et al., 2017) according to the Bayesian Information Criterion (BIC) [plastome (full and reduced): TVM $+\mathrm{F}+\mathrm{R} 3$; rDNA cistron: GTR + F + R2; ITS: SYM + I + G4; TLF: K3Pu + FR4]. Each search was performed through the automated computation of 20 Maximum Likelihood (ML) starting trees from 98 alternative randomized Maximum Parsimony (MP) trees, searching for bestscoring ML trees and estimating branch support for the best tree from 1,000 bootstrap replicates (BS) using the ultrafast bootstrap

${ }^{5}$ http://www.genecodes.com 
option (Minh et al., 2013; Chernomor et al., 2016) implemented in the software.

Ancestral divergence ages of the Fernandezian and other Loliinae grasses were estimated from the concatenated ITS-TLF data set with BEAST 2 (Bouckaert et al., 2014). We imposed independent site substitution models, lognormal relaxed clock and Yule tree models (Minaya et al., 2017). Two nodes of the Poaceae tree were calibrated using secondary age constrains for the crown nodes of the BOP clade (Oryza + Pooideae) (normal prior mean $=51.9 \mathrm{Ma}, S D=1.9)$ and the Brachypodium + core pooids clade (Brachypodium + Aveneae-Poeae) (normal prior mean $=30.9 \mathrm{Ma}, S D=3.5$ ), following the grass-wide plastome based dating analysis of Sancho et al. (2018) and a third node was calibrated using a minimum age constrain $(16 \mathrm{Ma})$ for the crown node of the fine-leaved Loliinae (lognormal prior mean $=19.5$ $\mathrm{Ma}, S D=0.101$ ) based on a Festuca leaf macrofossil from Poland dated to the Early Miocene showing Festuca sect. Festuca-type adaxial and abaxial epidermises (Juchniewicz, 1975). We also imposed a broad uniform distribution prior for the uncorrelated lognormal distribution (ucld) mean (lower $=1.0 \mathrm{E}-6$; upper $=0.1$ ) and an exponential prior for ucld standard deviation (SD). We ran 600 million Markov chain Monte Carlo (MCMC) generations in BEAST2 with a sampling frequency of 1,000 generations. The adequacy of parameters was checked using TRACER v.1.6 ${ }^{6}$ with all the parameters showing Effective Sample Size (ESS) $>200$. A Maximum clade credibility (MCC) tree was computed after discarding $10 \%$ of the respective saved trees as burn-in.

\section{Ancestral Range Estimation}

We used the parametric dispersal-extinction-cladogenesis (DEC) approach implemented in Lagrange v. 20130526 (Ree and Smith, 2008) to infer global extinction and dispersal rates and ancestral range inheritance scenarios for each node representing the ancestors of the Fernandezian and other Loliinae grasses in the maximum clade credibility (MCC) tree obtained from BEAST. We defined 13 Operational Areas (OAs) (A-M), selected according to the current distribution ranges of the species and the potential historical distributions of their ancestors, delimited by geographical features that could have acted as barriers to dispersal (Minaya et al., 2017) (Supplementary Table S2A). Specifically, we selected four American OAs: North America (H), northern South America (I), southern South America (J), and Juan Fernandez (M), aiming to recover the areas of origin of the ancestors of Megalachne and Podophorus that presumably colonized the Juan Fernandez archipelago from the American mainland through long-distance dispersal (LDD). The ancestral ranges were built imposing a maximum of two ancestral areas (AA), considering that ancestors were not more widespread than their extant descendants (Sanmartín, 2003). Ancestral range inheritances and biogeographic events were inferred from a stratified model with four temporal windows (TSI: Late Oligocene to Middle Miocene, 28.4-16.0 Ma; TSII: Middle to Late Miocene, 16.17.2 Ma; TSIII: Late Miocene to Pliocene, 7.3-2.6 Ma; TSIV: Quaternary, 2.61-0 Ma). This model included the different

\footnotetext{
${ }^{6} \mathrm{http} / / /$ beast.bio.ed.ac.uk/Tracer
}

temporal paleogeographical configurations of the Americas and other continents that might have affected the evolution and the distribution of the main Fernandezian and other Loliinae lineages (Supplementary Table S2B). In order to obtain a more detailed fine-scale reconstruction of the biogeographic events that resulted in the Fenandezian grasses, a second DEC analysis was performed for the lineages of the AmericanVulpia-Pampas clade where the Fernandezian subclade was nested within (see section Results). This second analysis was performed using a pruned MCC dated subtree for the AmericanVulpia-Pampas clade and five OAs representing the current and paleo-geographical distributions of the lineages (H-NorthCentral America, N-Pampas-Ventania, O-Andes, P-Masatierra, Q-Masafuera; Supplementary Tables S2C,D).

\section{RESULTS}

\section{Loliinae Genome Sequence Data, Plastomes, and Nuclear rDNA Cistrons}

Most of the studied Loliinae genome-skimming sequenced samples, including the newly studied Festuca asplundii, F. caldasii, F. holubii, F. procera, and F. quadridentata, yielded a large number of PE reads, ranging from 9,863 to 40,669 kbp (Table 1 and Supplementary Table S1). The two Megalachne samples were below that threshold (M. berteroniana 5,288 $\mathrm{kbp}$; M. masafuerana 6,134 kbp) but showed high quality reads. The 164 years old Podophorus bromoides type specimen sample rendered 6,694 kbp poor quality PE reads (Table 1 and Supplementary Table S1).

Most plastid assemblies produced a single plastome contig with a deep coverage of $>50 \mathrm{x}$ per sample that contained its two inverted repeat regions (IRa, IRb). However, Novoplasty assemblies of Festuca durandoi, F. spectabilis, F. superba, F. molokaiensis, F. abyssinica, and Megalachne berteroniana gave several small contigs and their full plastome assemblies were constructed with these contigs and the read mapping approach using Geneious and plastomes of their closest species as references. Plastome lengths of broad-leaved Loliinae ranged from 134,231 to $134,734 \mathrm{bp}$ and those of fine-leaved Loliinae from 132,599 to $133,869 \mathrm{bp}$; these values agreed with the plastome lengths retrieved by Hand et al. (2013) for their two main Loliinae group taxa. The lengths of the Megalachne berteroniana (132,812 bp) and M. masafuerana (132,826 bp) plastomes fell within the fine-leaved Lolinae range. The PE reads of the newly assembled plastomes were deposited in GeneBank under BioProject PRJNA626668 ${ }^{7}$ with accessions numbers SAMN14647043-SAMN14647077 and SAMN14668162 (Table 1 and Supplementary Table S1). The full Loliinae plastome MSA is available in Github ${ }^{8}$. The Podophorus bromoides plastid consensus sequence (total length $\sim 69,238 \mathrm{bp}$ ) covered different non-overlapping fragments of the aligned Loliinae plastomes $(\sim 40.7 \%)$ with a low coverage depth (10x to $1 \mathrm{x})$. The plastid

\footnotetext{
${ }^{7}$ https://www.ncbi.nlm.nih.gov/sra/PRJNA626668

${ }^{8}$ https://github.com/Bioflora/Loliinae_plastomes
} 
P. bromoides sequence (with its nucleotide positions mapped against the full Loliinae plastome MSA) is available in Github ${ }^{9}$.

We obtained a single contig of 6,453-6,455 bp for the rDNA cistrons of the studied Megalachne and other Loliinae samples. Coverage depth was relatively constant across the rDNA cistron sequences in most cases $(>10 \mathrm{x})$. The newly sequenced rDNA cistrons were deposited in GeneBank with accessions numbers MT145276-MT145310 (Table 1). The low quality genomic sequence available in the DNA obtained from the $P$. bromoides specimen resulted in a low number of PE reads, which precluded the readmerging of its full rDNA cistron; however, it allowed the assembly of its entire ITS region (Table 1 and Supplementary Table S1). The nuclear rDNA cistron of the studied Megalachne and other Loliinae grasses had a conserved structure along its transcriptional unit of 6-6.5 kb length, containing the 5'-ETS (724 bp), the $18 \mathrm{~S}$ gene $(1,818 \mathrm{bp})$, the ITS (585 bp), and the $25 \mathrm{~S}$ gene $(3,408 \mathrm{bp})$ regions of similar mean length to those of other grasses.

${ }^{9}$ https://github.com/Bioflora/Podophorus_plastome
The nuclear ITS locus and the plastid trnLF and trnTL loci were filtered, respectively, from the assembled rDNA cistrons and plastomes for the Megalachne and Loliinae samples (Table 1 and Supplementary Table S1). For P. bromoides, the complete ITS sequence was recovered with a coverage depth ranging from $10 \mathrm{x}$ to $1 \mathrm{x}$ and was deposited in Genbank under accession code MT022522 (Supplementary Table S1). Up to 60 and 70\% of, respectively, the $P$. bromoides $\operatorname{trn} \mathrm{LF}$ and $\operatorname{trn} \mathrm{TL}$ sequences were recovered with a coverage depth of 10x (MSAs available in Github) (see footnote 9). The ITS and TLF sequences of the newly analyzed $F$. andicola, $F$. longipes, $F$. vaginalis, and $F$. valdesii were incorporated to the study and were deposited in Genbank under accession codes EF584922-EF592955-EF585009; KY368804KY368856-KY368907; $\quad$ EF584977-EF584977-EF585111; MT022522-MT040974 - MT040975 (Supplementary Table S1).

\section{Loliinae Plastome and Nuclear Phylogenomic Trees}

The full plastome data set (two Megalachne and 33 additional Loliinae samples) included 133,894 filtered positions of

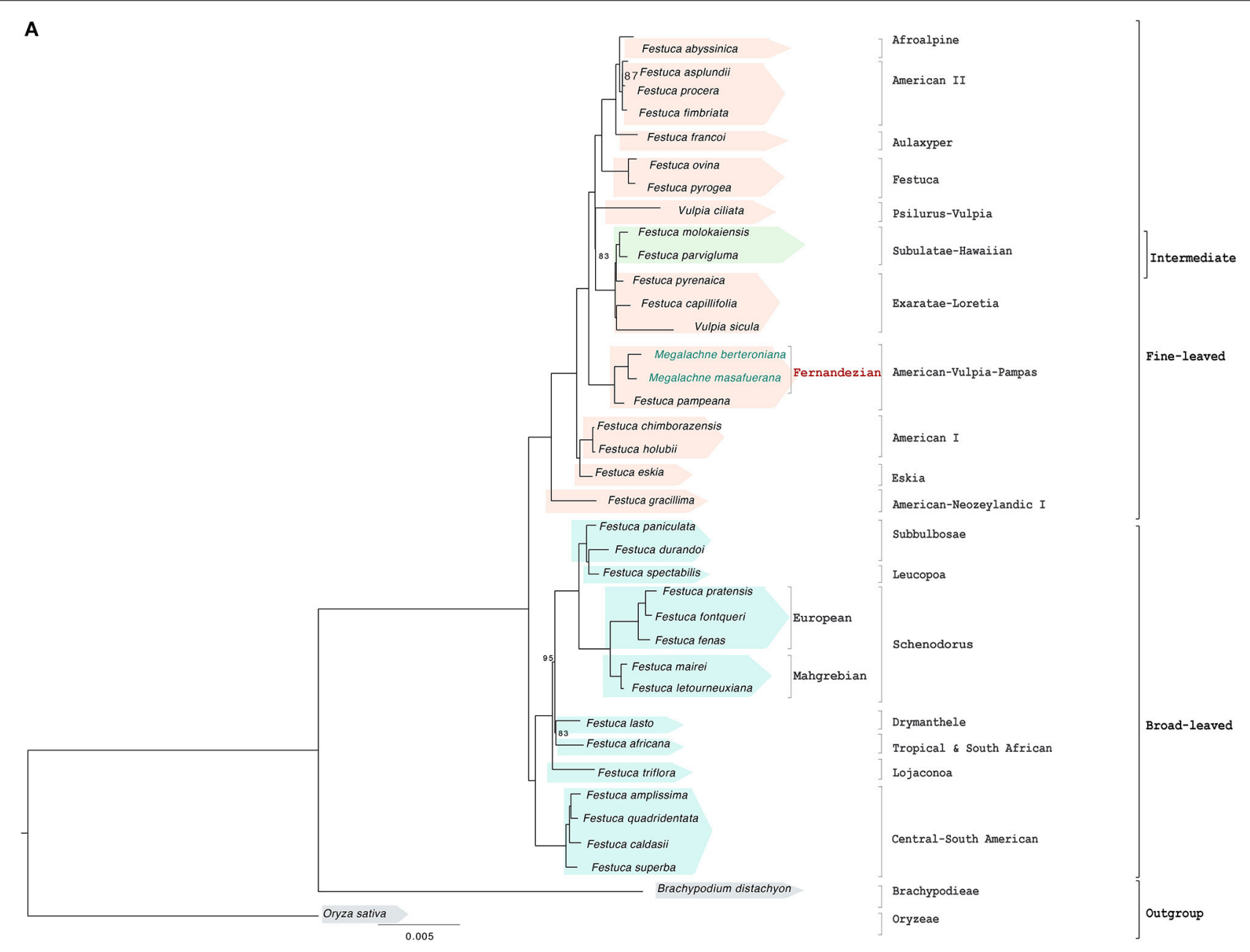

FIGURE 2 | Continued 


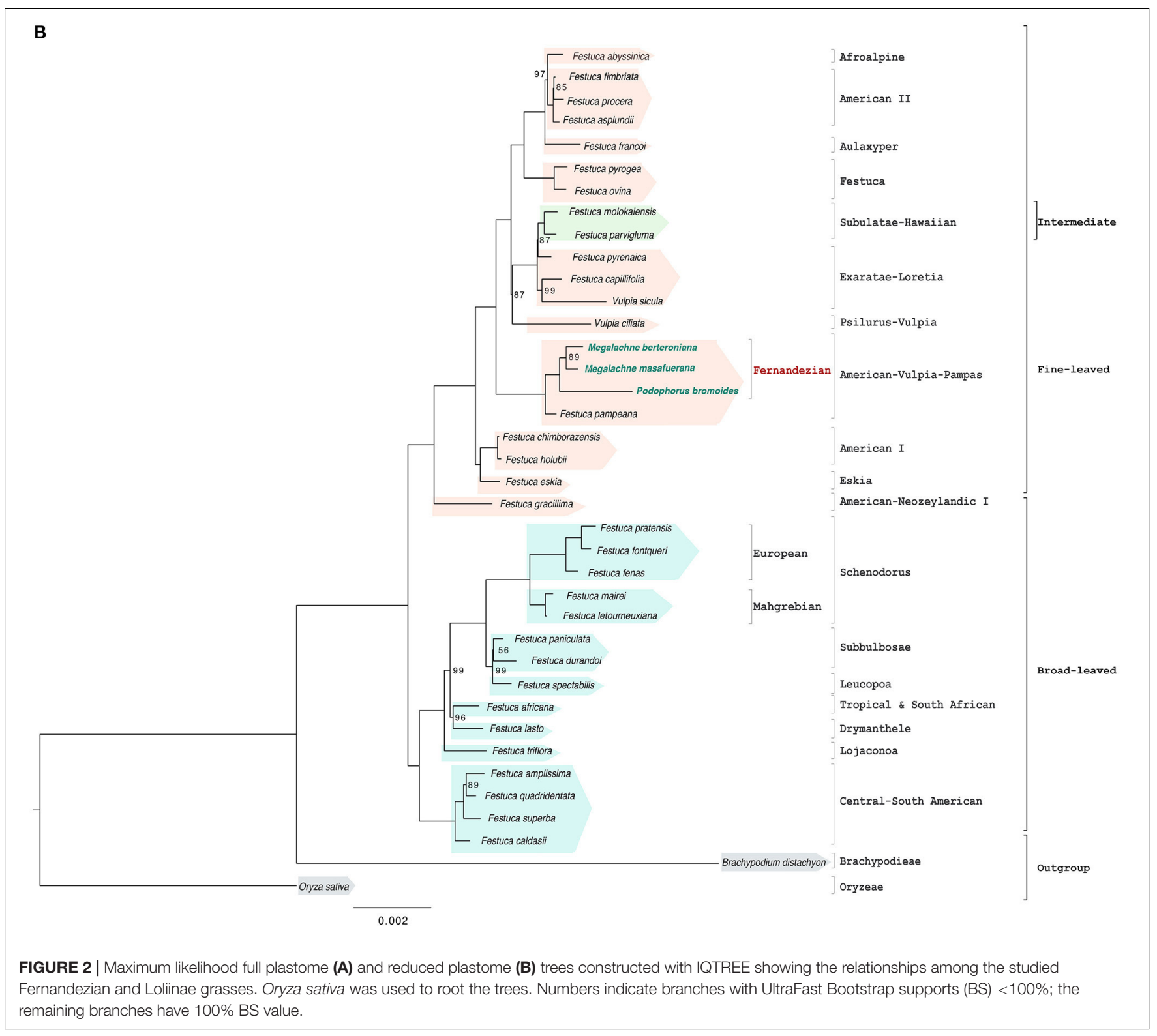

which 7,480 were variable and 4,160 potentially informative. The best plastome ML phylogenetic tree (Figure 2A and Supplementary Figure S1A) recovered a fully resolved and highly supported topology with most branches having 100\% bootstrap support (BS), and only three (94-99\% BS) and one (77\% BS) branches having strong to relatively good support. This Loliinae phylogenomic tree based on plastome data showed a main split of broad vs. fine-leaved Loliinae lineages, and successive splits within both the broad-leaved (Central-South American, Lojaconoa, Drymanthele/Tropical and South African, Leucopoa, Subbulbosae, Schedonorus) and the fine-leaved (American-Neozeylandic I, Eskia/American I, American-VulpiaPampas, Psilurus-Vulpia/Exaratae-Loretia (with intermediate Subulatae-Hawaiian nested within), Festuca, Aulaxyper, American II, Afroalpine) clades. Megalachne berteroniana and
M. masafuerana plastome sequences formed a Fernandezian clade, sister to $F$. pampeana and nested within the southern American American-Vulpia-Pampas clade. Newly sequenced South American plastome samples fell within the fine-leaved American II [F. fimbriata, (F. asplundii, F. procera)] and American I [(F. holubii, F. chimboracensis $)]$ clades, and within a Central-South American broad-leaved clade $[(F$. caldasii, (F. superba, (F. quadridentata, F. amplissima)))]. Fuegian $F$. pyrogea fell within the fine-leaved Festuca clade and the broadleaved F. fenas clustered within the European Schedonorus clade (Figure 2A and Supplementary Figure S1A).

The reduced plastome data set, which included the Podophorus sample, had 55,872 positions of which 5,989 were variable and 823 potentially informative. The optimal ML tree (Figure 2B and Supplementary Figure S1B) 
recovered a topology that was also fully resolved and almost identical to that of the complete plastome data, though the branch support was slightly lower across the phylogenomic tree [all braches with full support except seven branches with strong (90-99\%), three with good (70-89\%), and one with weak (60\%) BS]. In this phylogenomic tree, $P$. bromoides was resolved as sister to the Megalachne subclade $(90 \%$ BS) and formed a fully supported Fernandezian clade, which was nested within the American-Vulpia-Pampas lineage (Figure $2 \mathbf{B}$ and Supplementary Figure S1B).

The nuclear rDNA cistron data set (two Megalachne and 33 additional Loliinae samples) included 6,455 positions of which 502 were variable and 321 potentially informative. The

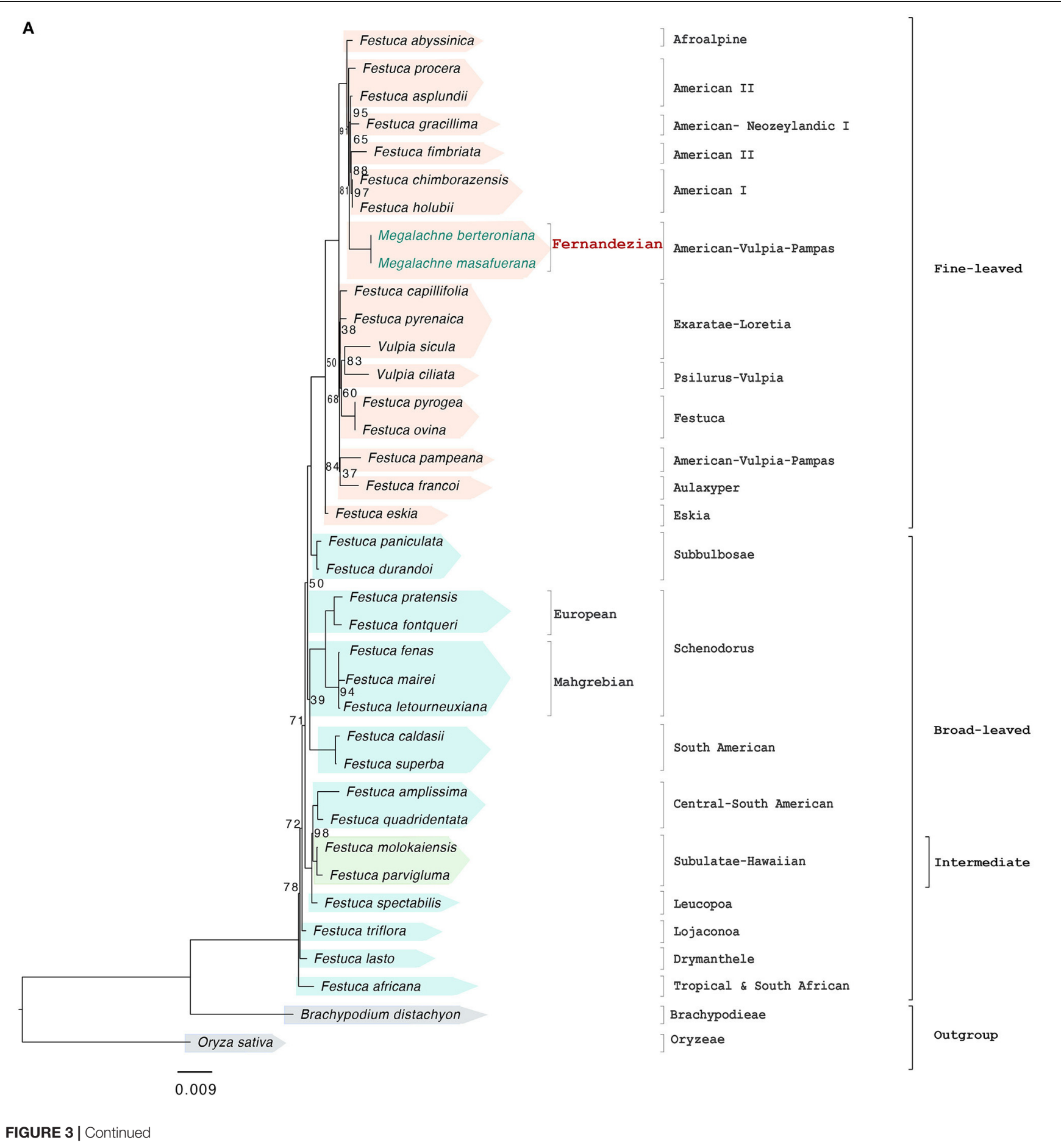




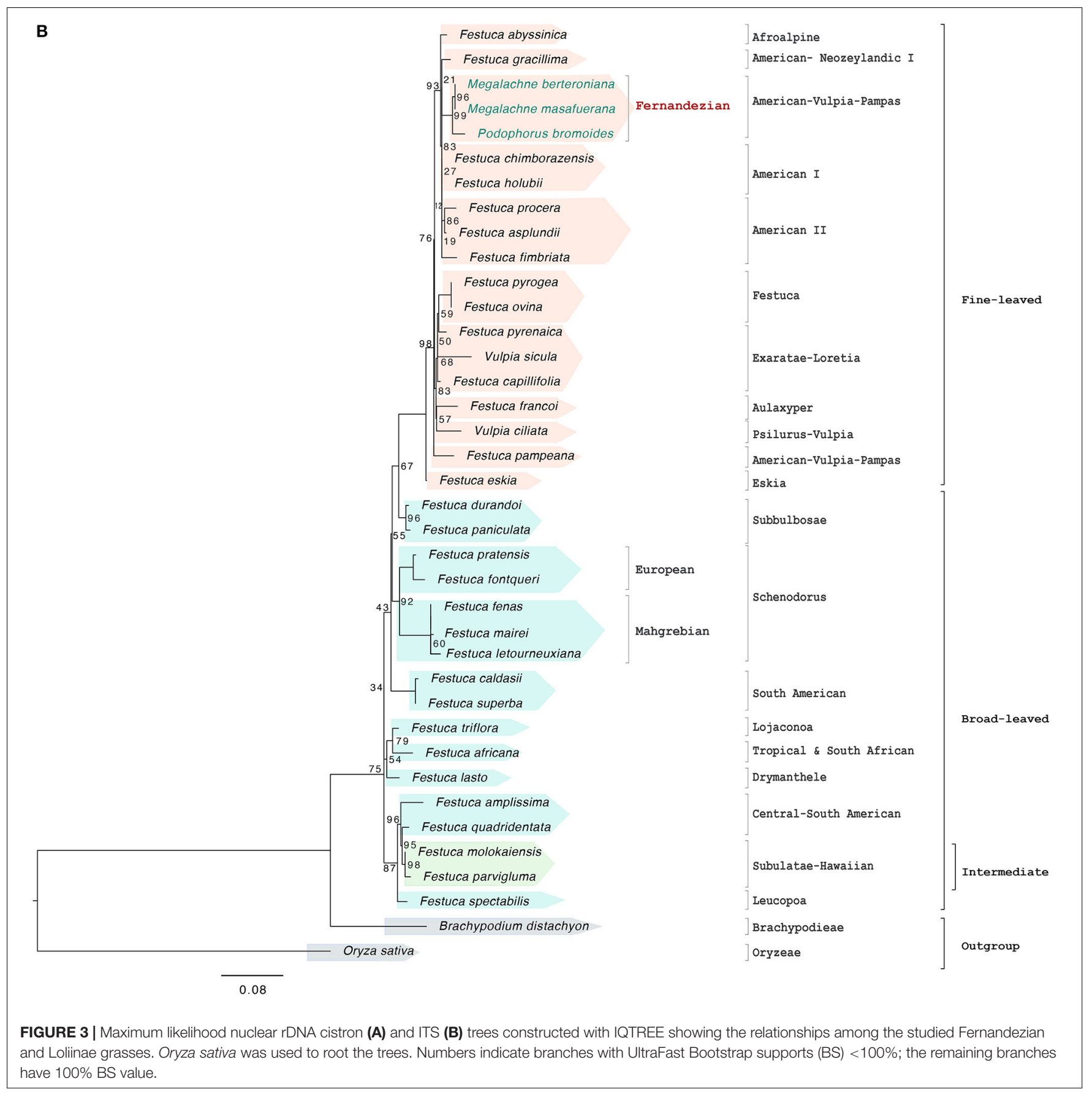

best ML tree (Figure 3A and Supplementary Figure S1C) retrieved a fully resolved topology; however, some internal branches were very short and showed very low support [21 branches with strong (90-99\%), seven with good (70$89 \%)$, and seven with weak $(60 \%)$ or very weak $(<50 \%)$ BS]. The rDNA cistron-based phylogenetic tree showed the successive divergences of early diverging paraphyletic broadleaved lineages (Tropical and South African, Drymanthele, Lojaconoa, Leucopoa, Central-South American, SouthAmerican, Schedonorus, Subbulbosae), which were in most cases poorly supported and included the intermediate Subulatae-Hawaiian nested within, and the more recent split of the strongly supported fine-leaved clade (97\% BS). The topology of the fine-leaved group showed successive weakly to strongly supported lineage splits [(Eskia, ((Aulaxyper, Exaratae-Loretia, Festuca), (American-Vulpia-Pampas, PsilurusVulpia, Afroalpine, American-Neozeylandic I, American I, American II)))]. Megalachne berteroniana and M. masafuerana formed a fully supported Fernandezian clade based on the cistron sequences; this clade was close to other species of 
the American I (F. holubii, F. chimborazensis) and American II (F. asplundii, F. fimbriata, F. procera) assemblages, which together with the American-Neozeylandic I F. gracillima formed a well-supported fine-leaved South American clade (91\% BS). Festuca pyrogea was reconstructed as sister to $F$. ovina within the strong Festuca clade. Within the broad-leaved lineages, the strongly supported Central-South American (F. amplissima, F. quadridentata) and (F. superba, $F$. caldasii) clades were resolved in different positions across the broad-leaved subtree, and F. fenas clustered within the Mahgrebian Schedonorus subclade (Figure $\mathbf{3 A}$ and Supplementary Figure S1C). Phylogenetic reconstruction of filtered rDNA cistron sequences for the ITS region, together with that of $P$. bromoides, recovered the same overall tree topology, which showed a strong sister relationship of P. bromoides to the Megalachne clade (99\% BS) (Figure 3B and Supplementary Figure S1D).

\section{Plastid TLF, Nuclear ITS, and Combined ITS-TLF Phylogenetic Relationships}

The separate and combined TLF (2,205 positions, 501 variable, 240 informative), ITS (645 positions, 285 variable, 193 informative) and ITS-TLF analyses of 135 Loliinae and outgroup samples retrieved phylogenies (Supplementary Figures S2A-C) highly congruent with those obtained in previous studies. Additionally, these trees showed the evolutionary placements of the three Fernandezian species and of six South American and one South African newly studied Festuca taxa. Both the nuclear ITS and the plastid TLF recovered a highly supported Fernandezian clade (99\% BS) where $P$. bromoides was sister to the M. berteroniana/M. masafuerana subclade. Nonetheless, whereas the Fernandezian group was nested within a clade of American-Vulpia-Pampas taxa (69\% BS), clearly separated from the American I ( $82 \%$ BS), and American II+Afroalpine $(78 \%$ BS) clades in the TLF tree (Supplementary Figure S2A), it was nested within a large clade of American I + American II + Afroalpine taxa $(99 \%)$ that also included some (F. ventanicola) but not all the American-Vulpia-Pampas species in the ITS tree (Supplementary Figure S2B). The combined ITS-TLF analysis placed the fully supported Fernandezian clade within a highly supported American-Vulpia-Pampas clade (97\% BS) and resolved $F$. ventanicola as the strong sister lineage of the Fernandezian grasses (100\% BS) (Supplementary Figure S2C). The TLF and ITS evolutionary placements of the newly sequenced South American taxa agreed with those of the plastome and rDNA trees and were overall congruent to each other. The fine-leaved F. asplundii and $F$. procera were nested within the American II + Afroalpine clade and F. holubii within the American I clade in the TLF tree (Supplementary Figure S2A), whereas the three of them fell within the large American I + American II + Afroalpine clade in the ITS tree (Supplementary Figure S2B). The sister F. asplundii/F. andicola (69\% BS) and F. holubii/F. glumosa (87\% BS) relationships observed in the ITS tree and their phylogenetic placements in the combined ITS-TLF tree (Supplementary Figure S2C) agreed with those of the plastid tree. The broad-leaved F. quadridentata and $F$. caldasii were nested within a large Central-South American-Eurasian-South African clade (97\% BS) in the TLF tree (Supplementary Figure S2A) and in separate Central-South American (74\% BS) and Eurasian-South American (62\% BS) clades in the ITS tree (Supplementary Figure S2B). Their positions in the combined ITS-TLF tree (Supplementary Figure S2C) agreed with those of the nuclear tree. The South African F. longipes was resolved as sister of South African F. scabra (99\% BS) in the TLF tree (Central-South American-Eurasian-South African clade) and of Tropical-South African F. costata in the ITS (100\% BS) and combined ITS-TLF ( $88 \%$ BS) trees (Tropical-South African clade) (Supplementary Figures S2A-C).

\section{Dating Analysis and Ancestral Range Inheritance Reconstruction}

The Bayesian ITS-TLF MCC tree constructed with Beast2 (Figure 4 and Supplementary Figure S3) yielded a similar topology to that retrieved in the ML analysis (Supplementary Figure S2C). The age of stem and crown Loliinae nodes were estimated to Late-Oligocene (median $21.47 \mathrm{Ma}$ ) and Early Miocene (19.4 Ma), respectively, whereas Early and Mid-Miocene divergences were inferred for the splits of the broad (16.31 Ma) and fine-leaved (16.83 Ma) lineages. An older Mid-Miocene origin was estimated for the ancestor of the American-Vulpia-Pampas clade (7.74 Ma) than for the younger Late-Miocene-to-Pliocene ancestors of the remaining fine-leaved [American II+Afroalpine (5.39 Ma); American I (3.89 Ma)] and broad-leaved [South-American (5.04 Ma); Central-South American (3.32 Ma)] South American Loliinae lineages (Figure 4 and Supplementary Figure S3). The ancestor of the Fernandezian clade was inferred to have originated between the Late-Miocene (5.15 Ma; stem node) and the Pliocene (2.72 Ma; crown node), corresponding to the estimated split of Podophorus and Megalachne, whereas the split of the two Megalachne species was estimated to have occurred in the Pleistocene (1.02 $\mathrm{Ma}$, Calabrian). The estimated ages of the Fernandezian ancestors predated those inferred for the ancestor of other oceanic endemic Loliinae lineages [e.g., Canarian fineleaved Aulaxyper (4.11-2.84 Ma; Pliocene); Hawaiian F. aloha/F. molokaiensis (1.89-1.16 Ma; Lower-to-Recent Pleistocene); and recent Pleistocene Madeiran broadleaved F. donax (1.23 Ma, Calabrian) and Reunion Island fine-leaved $F$. borbonica (0.3 Ma, Ionian)] (Figure 4 and Supplementary Figure S3).

The ancestral range inheritance scenarios of Loliinae inferred from our Lagrange stratified Loliinae DEC model (-ln likelihood 404.6) had a global estimated dispersal rate (dis: 0.09385) 5.5 times higher than the estimated extinction rate (ext: 0.01536) (Figure 5A). The ancestors of Loliinae and of the broad-leaved and fine-leaved clades were inferred to have originated in uncertain widespread areas of the northern hemisphere (Mediterranean basin, Northern-Central America, 


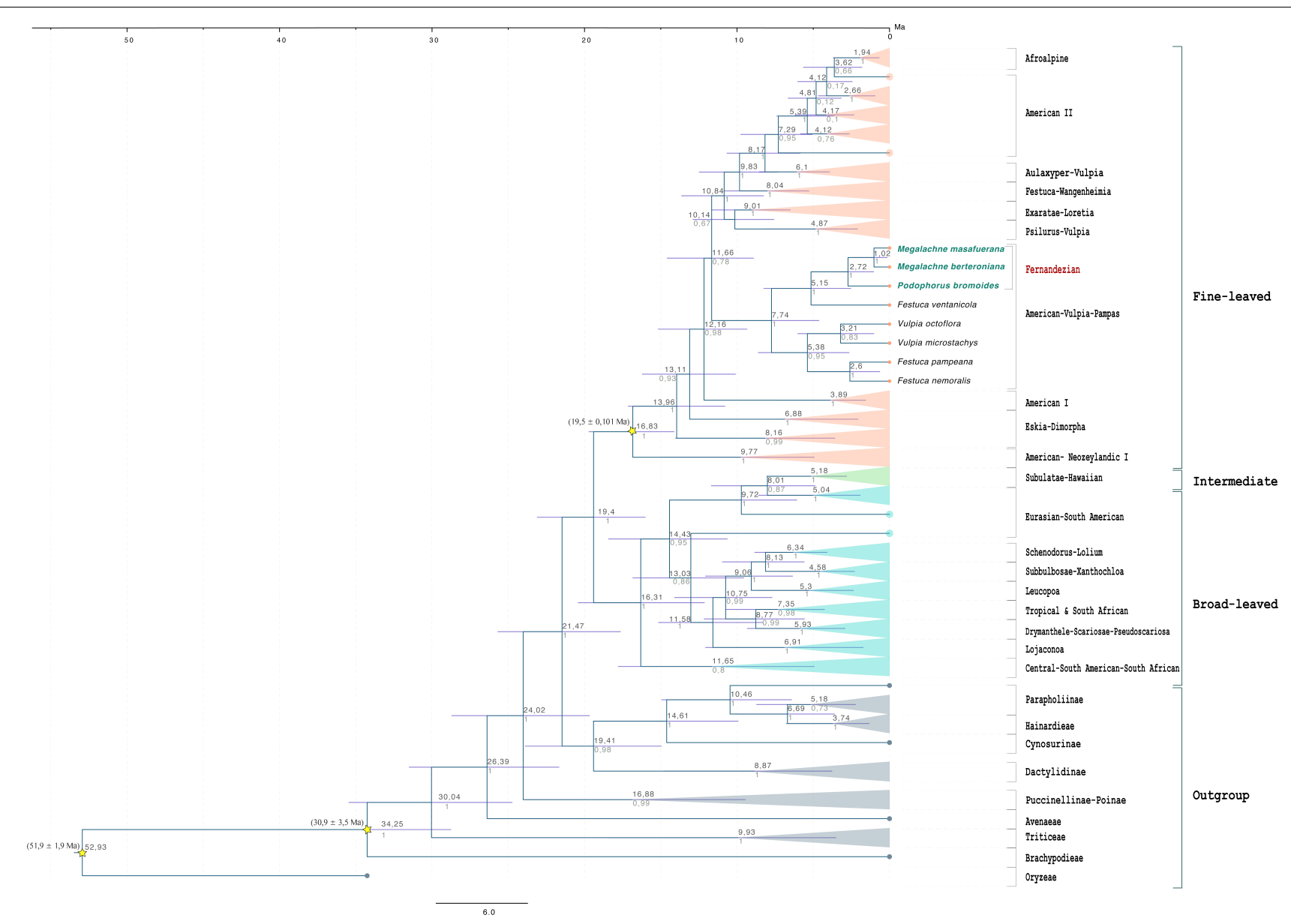

FIGURE 4 | Schematic Bayesian maximum clade credibility dated chronogram of 135 Loliinae taxa constructed with BEAST2 using nuclear ITS and plastid TLF loci showing estimated nodal divergence times (medians, in Ma) and 95\% highest posterior density (HPD) intervals (bars) above branches and Posterior Probability Support (PPT) values below branches. Stars indicate secondary nodal calibration priors (means \pm SD, in Mya) for the crown nodes of the BOP, Brachypodium + core pooids, and fine-leaved Lolinae clades.

Eurasia) in the transition between the Late Oligocene and the Early Miocene. Most of the transcontinental LDDs of both fine-leaved and broad-leaved Loliinae ancestors were estimated to have occurred during the Miocene and the Pliocene (time slices TSII-TSIII), and a few more during the Pleistocene (time slice TIV) (Figure 5A). According to our DEC model, the South American subcontinent was simultaneously colonized by broad and fine-leaved Mediterranean ancestors, which arrived, respectively, to the northern and southern South American ranges around the Mid-Miocene (Figures 4, 5A). Within the fine-leaved lineage, a Mid-Miocene vicariance was inferred to have originated the American-Vulpia-Pampas ancestor in southern South America $\sim 7.74 \mathrm{Ma}$. This ancestor would have then experienced range expansions to either North-Central America originating the southern American Pampean-Andean and the North-Central American Vulpia clade and to the Juan Fernandez archipelago originating the Pampean-Fernandezian clade at the end of the Neogene. Our stratified Loliinae DEC model suggested that the colonization of the Juan
Fernandez archipelago from a mainland ancestor in southern South America could have occurred in the Mid-to-Late Miocene (7.74-5.15 Ma) (Figures 4, 5A). According to this hypothesis, the ancestor of $F$. ventanicola and the Fernandezian Podophorus and Megalachne grasses was distributed in a widespread southern South America-Juan Fernandez area during the Late Miocene (5.15 Ma). A vicariance event was invoked to explain the split of the common ancestor into the current mainland Pampean-Ventanian endemic lineage and the Fernandezian ancestor, which was inferred to be present in the archipelago in the mid-Pliocene ( 2.72 Ma) (Figures 4, 5A). A more detailed reconstruction of the biogeography of the Fernandezian grasses within their archipelago was obtained in our second American-VulpiaPampas DEC model (-ln likelihood 406.2; dis: 0.08232; ext: 0.0497) (Figure 5B). According to this model: (i) the ancestor of the American-Vulpia-Pampas could have been distributed in the Pampas-Ventanian range during the Miocene $(7.74 \mathrm{Ma})$; (ii) this ancestor presumably experienced a range expansion to Masatierra and was present in a widespread 


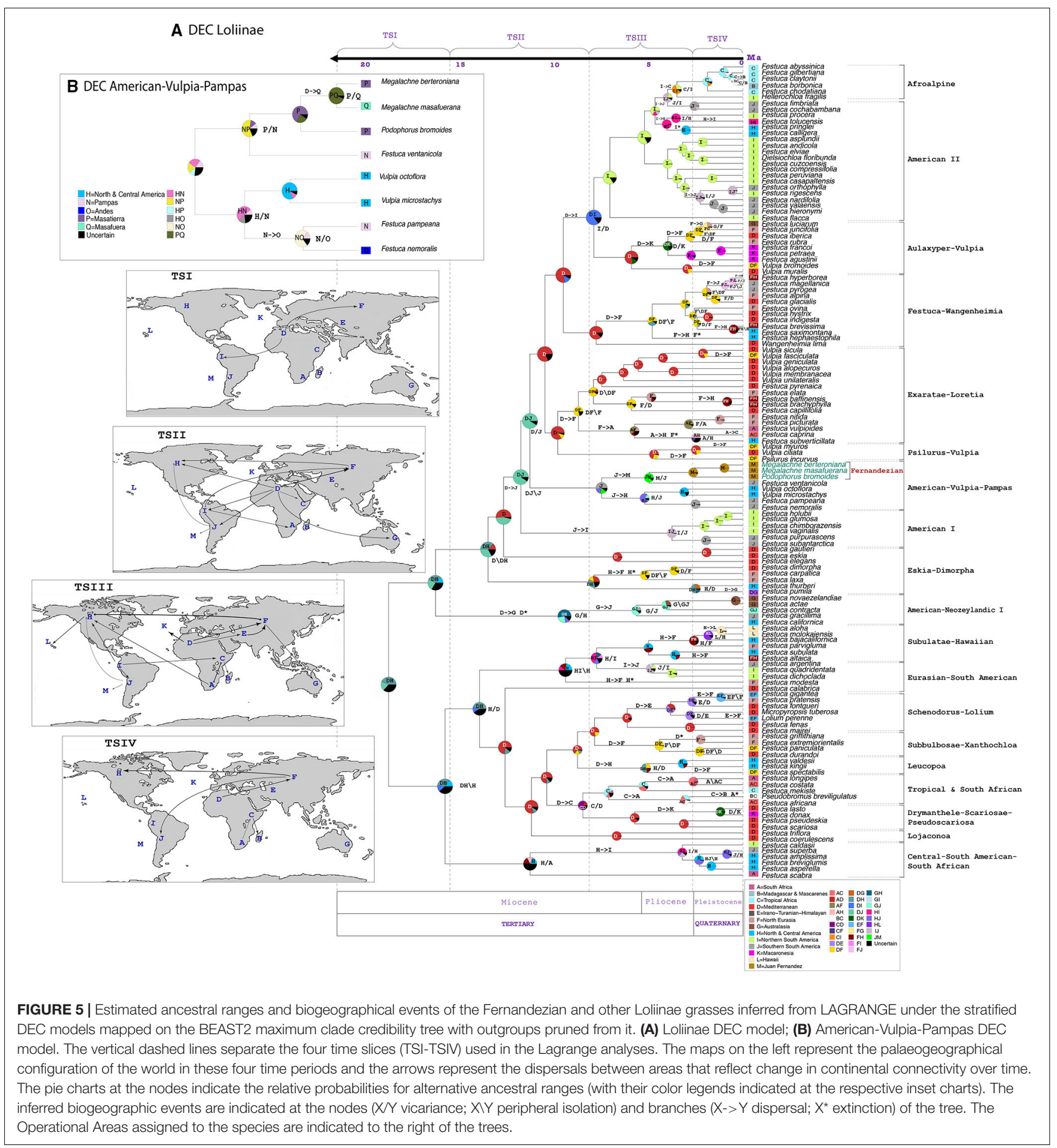

Pampas-Fernandezian area during the Late Miocene (5.15 Ma); (iii) after a Pampas-Ventanian/Masatierra vicariance, the ancestor of the Fernandezian grasses was present in Masatierra during the Late Pliocene (2.72 Ma); (iv) an in situ speciation event originated the Podophorus lineage in Masatierra at that time; (v) a range expansion from
Masatierra to Masafuera placed the ancestor of the Megalachne clade in the two main Juan Fernandez islands during the Pleistocene (1.02 Ma); (vi) a recent vicariance would explain the respective speciations of $M$. berteroniana in Masatierra and of M. masafuerana in Masafuera during the last million years (Figures 4, 5B). 


\section{DISCUSSION}

\section{Phylogenetics of Megalachne and Podophorus: The Loliinae Fernandezian Clade}

Our museomic approach, based on the combined use of old and recent herbarium samples and of genome skim data, have allowed us to disentangle the evolutionary origins of the neglected Megalachne and Podophorus grasses. Complete and partial plastomes as well as the nuclear rDNA cistron and ITS data supported the phylogenetic placement of the studied Fernandezian Podophorous bromoides, Megalachne berteroniana, and M. masafuerana species within the AmericanVulpia-Pampas fine-leaved Loliinae clade (Figures 2, 3 and Supplementary Figures S1A-C). Our results corroborate the early suggestions of Tateoka (1962) who indicated a close affinity of Megalachne to Festuca based on shared morphological and serological traits, and the recent phylogenetic findings of Schneider et al. $(2011,2012)$ and Tkach et al. (2020) who placed them within the fine-leaved Loliinae, and definitively discard its classification within either Bromeae or Duthieinae. Our results have also contributed to enlarge the paraphyly of Festuca, which now accounts to up to 14 Loliinae genera nested within its main fine-leaved (Ctenopsis, Dielsiochloa, Hellerochloa, Megalachne, Micropyrum, Narduroides, Podophorus, Psilurus, Vulpia, Wangeheimia), intermediate (Castellia), and broad-leaved (Lolium, Micropyropsis, Pseudobromus) lineages (Supplementary Figure S2C; Inda et al., 2008; Minaya et al., 2017).

Our study has demonstrated the utility of museomics to disentangle the evolutionary history of the extinct Podophorus bromoides from its 164 years old type specimen. This adds a new extinguished species to the tree-of-life, resolving its phylogenetic position within the grasses, as done before for other exterminated plants, such as Sicyos villosus within Cucurbitaceae (Sebastian et al., 2010) Hesperelaea palmeri within Oleaceae (Van de Paer et al., 2016; Zedane et al., 2016), Haplostachys linearifolia and Stenogyne haliakalae within Lamiaceae (Welch et al., 2016) and Chasechloa egregia within Poaceae (Silva et al., 2017). Moreover, our phylogenetic analyses based on plastome and rDNA-based data have demonstrated that $P$. bromoides is strongly resolved as sister to the Megalachne clade (M. berteroniana, M. masafuerana) (Figures 2B, 3B and Supplementary Figures S2A-C), rejecting thus the moderately supported sister relationship found for the Masatierra taxa (i.e., P. bromoides and M. berteroniana, $72 \%$ BS) in a previous phylogenetic analysis based on partial ITS sequences from some samples (Podophorus bromoides ITS1 only) (Schneider et al., 2011).

Our Loliinae-wide phylogenomic analyses have further identified the relict Pampean-Ventanian fescues as the closest relatives of these fine-leaved endemic Fernandezian grasses. Phylogenies based on complete and partial plastome data indicate that Megalachne and Podophorus are strongly related to the American-Vulpia-Pampas lineage, represented by $F$. pampeana (Figure 2 and Supplementary Figure S2A). By contrast, the nuclear rDNA cistron and the ITS phylogenies place them within a large American I + American II group
(Figure 3 and Supplementary Figure S2B), an assemblage that also includes other American-Vulpia-Pampas species, such as F. ventanicola (Supplementary Figure S2B). However, the phylogenetic tree reconstructed with the combined ITS-TLF data strongly supports nesting the Fernandezian clade within the American-Vulpia-Pampas clade and its sister relationship to the Pampean-Ventanian endemic F. ventanicola (Figure 4 and Supplementary Figures S2C, S3). The incongruent placements of the Fernandezian grasses in the maternal plastome (plastid) vs. paternal rDNA cistron (ITS) Loliinae trees is a general feature of many Southern Hemisphere Loliinae species that reflect their hybrid allopolyploid nature (Inda et al., 2008; Minaya et al., 2017). Evolutionary studies have illustrated the different topological placements of known allopolyploid Loliinae species in plastid vs. nuclear trees (e.g., allotetraploid F. fenas, allohexaploid F. arundinacea, Inda et al., 2014; allotetraploid F. simensis, Inda et al., 2014; Minaya et al., 2015; allohexaploid F. nigrescens, Kergunteuil et al., 2020). Karyological and genome size reports have further shown that all southern hemisphere Loliinae species studied so far are polyploids (Dubcovsky and Martínez, 1992; Connor, 1998; Namaganda et al., 2006; Smarda and Stancik, 2006). Therefore, the incongruent positions shown by the American I clade polyploids $F$. chimborazensis $(4 x), F$ vaginalis $(4 x), F$. glumosa $(4 x), F$. purpurascens $(6 x)$, American-Vulpia-Pampas clade $F$. ventanicola $(4 x)$ and the putative South African polyploid F. longipes in our plastid and nuclear trees (Supplementary Table S1 and Supplementary Figures S2A,B) indicate that these taxa probably originated from interspecific hybridization followed by genome doubling. Although genome size or chromosome counting data are lacking for the Fernandezian P. bromoides and M. berteroniana and M. masafuerana species, their equivalent contrasting positions in the plastid and nuclear trees suggest that these endemic grasses are also allopolyploids. It is further supported by the fact that most of the remaining members of the AmericanVulpia-Pampas clade are also polyploids [e.g., F. pampeana ( $8 x)$, F. nemoralis (8x), V. microstachys (6x); Dubcovsky and Martínez, 1992; Smarda and Stancik, 2006; Díaz-Pérez et al., 2014]. Further investigation of these genomic data using the methodology described in Viruel et al. (2019) together with customized genome size analyses from fresh or herbarium samples (Smarda and Stancik, 2006) might reveal the ploidy level of these rare taxa.

Megalachne and Podophorus show a "vulpioid" phenotype, having lax panicles and long awned lemmas (Figure 1). These are characteristic traits of Vulpia and few other Lolinae lineages (Catalan et al., 2007). Vulpia and other ephemeral Loliinae genera, such as Ctenopsis, separate from Festuca based on their annual habit, four or less fertile florets per spikelet, largely unequal glumes, and long awned lemmas, which together distinguish them from the typical festucoid phenotype of Festuca and other robust Loliinae, characterized by their perennial habit, four or more fertile florets per spikelet, subequal glumes, and muticous or usually shortly awned lemmas, though none of them is absolute (Catalan et al., 2007). The origins of the polyphyletic Vulpia lineages are still intriguing although analysis of cloned single copy genes have demonstrated that some allopolyploid Vulpia species bear heterologous copies 
derived from morphologically close diploid relatives (Díaz-Pérez et al., 2014). The homoplasic "vulpioid" inflorescence phenotype has also appeared in other perennial Loliinae lineages, like the northern South America Dielsiochloa floribunda (American II clade), and in some species of Festuca. Interestingly, the slender cespitose Pampean-Ventanian endemic F. ventanicola shares its "vulpioid" phenotype with its sister Fernandezian Megalachne and Podophorus taxa (Figure 1), suggesting that they could have inherited it from their common ancestor. The long awn is an important dispersal trait in several annual grasses, including the invasive Vulpia species (Catalan et al., 2007; Díaz-Pérez et al., 2014), allowing the caryopsis to attach to the feathers or furs of animals and to be dispersed to long distances (Linder et al., 2018). It could be thus hypothetised that the presumed "vulpioid" ancestor of the Fernandezian grasses could have migrated to the isolated Juan Fernandez archipelago transported by epizoochory or endozoochory through pelagic birds. Interestingly, Podophorus bromoides shows an extremely reduced spikelet (Figure 1), being the only Loliinae taxon, together with Vulpia fontquerana Melderis \& Stace (Torrecilla et al., 2004) having a single fertile floret (with a reduced sterile floscule) per spikelet. This, together with its apparent ephemeral habit might be associated to an overall trend toward an annual habit after its speciation in the Masatierra island (Figures 1, 5).

\section{Biogeography and Conservation of the Endemic Megalachne and Podophorus Grasses}

Our Loliinae and American-Vupia-Pampas biogeographic DEC analyses have elucidated the most likely colonization routes of the Fernandezian ancestors, and the speciation events that originated Podophorus and Megalachne taxa in Masatierra and Masafuera (Figures 1, 5). Our ancestral range analyses identified the Pampean-Ventanian region to be the most likely place of origin for the common ancestors of the Fernandezian endemic grasses (Figures 5A,B). The closest relatives of Podophorus and Megalachne are relict endemic species of the Ventanian region (F. ventanicola, F. pampeana; Catalan and Müller, 2012) a hotspot of plant and animal diversity (Crisci et al., 2001). The formation of the Ventanian range in the Paleoproterozoic-Ordovician time span ( 2,200-475 Ma; Ramos et al., 2014) largely preceded the Oligocene-Miocene uplifting of the North American (31-28 Ma) and Central-Southern Andean (10-5 Ma) cordilleras (Crisci et al., 2001; Wakabayashi and Sawyer, 2001) as well as the emergence of the volcanic Juan Fernandez archipelago islands (5.8 Ma) (Stuessy et al., 1984). Although the inferred ages of the American-VulpiaPampas clade (7.7 Ma), F. ventanicola + Fernandezian clade $(5.1 \mathrm{Ma})$ and Fernandezian clade $(2.7 \mathrm{Ma})$ ancestors (Figure 4 and Supplementary Figure S3) are younger than those of the Central-Southern Andes, the altitude and disposition of the austral Andean mountains was probably lower than in the present (Crisci et al., 2001). The geological time layout could have facilitated the hypothetical LDDs of the Ventanian ancestors to other American ranges and to the Juan Fernandez archipelago (Figures 1, 5). Our Loliinae and American-Vulpia-Pampas DEC models support a colonization of the Fernandezian archipelago from a southern South American Pampean-Ventanian ancestor in the late-Miocene 7.7-5.1 Ma (Figures 4, 5). The most recent estimate for that colonization concurs with the radiometric dating of the oldest Fernandezian islands (Santa Clara, $5.8 \pm 2.1$ Ma; Masatierra, $4.23 \pm 0.16 \mathrm{Ma}$ ) (Stuessy et al., 1984) which could have been united in the past (Sanders et al., 1987). We could thus infer that the Ventanian Fernandezian ancestors likely arrived at the paleo-island formed by Santa Clara and Masatierra during the Late Miocene (Figure 5), probably transported by birds. The estimated split of the Podophorus lineage from the Megalachne ancestor at 2.7 Ma suggest a late-Pliocene in situ speciation event in Masatierra for the origin of the endemic $P$. bromoides (Figure 4). Our regional DEC model and our dating analyses infer that the colonization of the Masafuera island occurred from Masatierra during recent Pleistocene times (1.02 $\mathrm{Ma}$ ), supporting in situ speciation events for M. berteroniana in Masatierra and M. masafuerana in Masafuera (Figures 4, 5B). The westward inter-island colonization likely took place after the emergence of the young Masafuera island in the early Pleistocene (2.44 $\pm 1.14 \mathrm{Ma}$ ) (Stuessy et al., 1984) and was probably favored by the short distance separating them (i.e., $180 \mathrm{~km}$, Figure 1). This distance has acted, however, as a strong geographic barrier to gene flow since the divergence of both species. Our biogeographic reconstruction for the Fernandezian Loliinae taxa agree with the hypothesis of higher levels of plant endemism in Masatierra compared to Masafuera, which are related to their respective distances to the closest mainland and their estimated ages (Stuessy et al., 2017). Our study has also identified the previously unknown South American ancestors of these endemic Fernandezian grasses, pointing to the relict Pampean-Ventanian region as their cradle (Figure 5B).

The rich endemic flora of Juan Fernandez archipelago is one of the most threatened on earth (Stuessy et al., 1998; Bernardello et al., 2006). Human impact on these islands, such as the introduction of environmentally aggressive herbivores, has probably caused the extinction of at least two endemic Fernandezian endemic plants during the last two centuries (Santalum fernandezianum Phil. and Podophorus bromoides; Bernardello et al., 2006; Danton et al., 2006). The latter extinct species was extremely rare; collected by Germain in 1854 and described by Philippi in 1856 from Masatierra (without a specific locotype), its existence was later mentioned by Johow in 1896 (Baeza et al., 2007). However, the plant was never seen again, even after exhaustive searches, and was therefore considered extinct (Stuessy et al., 1998, 2017; Baeza et al., 2007). All four Megalachne species are classified as threatened according to the IUCN categories of threat (Danton et al., 2006; Danton and Perrier, 2017; Penneckamp-Furniel, 2018; PenneckampFurniel and Villegas, 2019): M. berteroniana as Vulnerable, M. masafuerana as Endangered, $M$. dantonii as Critically Endangered, and $M$. robinsoniana as Endangered. Nonetheless, these IUCN assessments did not include a description of the employed IUCN criteria to classify the plants in their respective categories of menace. Several authors, however, have severe concerns about the threats posed to these endemic grasses by the introduced herbivores and by invasive plants (Stuessy et al., 1998; Bernardello et al., 2006; Danton et al., 2006; 
Danton and Perrier, 2017) and their survival in some inaccessible places to overgrazing pressure (Danton et al., 2006; Danton and Perrier, 2017). Rigorous populations censuses and population genetic studies of the more largely distributed $M$. berteroniana and M. masafuerana species, and of the recently described and still poorly known $M$. robinsoniana and $M$. dantonii species would be required to establish their adequate category of threat and to design appropriate conservation strategies. Historical collections have an enormous value for biogeographical studies. Several plants have gone to extinction in a few decades after human arrival due their high sensitivity to perturbation of their habitats and their low competitiveness, especially in oceanic islands (Sebastian et al., 2010; Van de Paer et al., 2016; Welch et al., 2016; Zedane et al., 2016; Silva et al., 2017). Regrettably, Podophorus bromoides sums up to the list of recently extinct plants although its museomic analysis has unveiled its historical biogeography.

\section{DATA AVAILABILITY STATEMENT}

All datasets generated for this study are included in the article/Supplementary Material.

\section{AUTHOR CONTRIBUTIONS}

PC designed the study. MM-A, IA, JV, and PC collected the samples. MM-A and JV developed the experimental work. PC, MM-A, JV, IA, and AS-R analyzed the data, interpreted the results, and revised the manuscript. $\mathrm{PC}$ and MM-A prepared the manuscript. All authors contributed to the article and approved the submitted version.

\section{FUNDING}

This study was funded by the Spanish Aragon Government and European Social Fund Bioflora A01-17R research grant. MM-A was supported by the University of ZaragozaSantander Ph.D. fellowship.

\section{ACKNOWLEDGMENTS}

We thank Tod Stuessy for sending us herbarium samples of Megalachne berteroniana and M. masafuerana, the Kew Herbarium for facilitating the sampling of the Podophorus bromoides isotype (K000433684), the Ministerio del Ambiente of Ecuador for giving permission to collect Loliinae samples in the Ecuadorian paramos (MAE-DNB-CM-2015-0016), Antonio Diaz-Perez for assistance with the filtering of the Brachypodium distachyon rDNA cistron and three reviewers for their valuable comments to an early version of the manuscript. The genome skimming data of 35 Loliinae samples was generated at the Centro Nacional de Análisis Genómicos (CNAG, Barcelona, Spain) and that of Podophorus bromoides at Kew Botanical Gardens (United Kingdom). The bioinformatic and evolutionary analyses were performed at the Escuela Politécnica Superior de Huesca (Universidad de Zaragoza, Spain) Bioflora laboratory.

\section{SUPPLEMENTARY MATERIAL}

The Supplementary Material for this article can be found online at: https://www.frontiersin.org/articles/10.3389/fpls.2020.00819/ full\#supplementary-material

FIGURE S1 | (A) Maximum likelihood full plastome cladogram (35 Loliinae taxa, Podophorus excluded) constructed with IQTREE showing the relationships among the studied Fernandezian and Loliinae grasses. Oryza sativa was used to root the trees. Numbers indicate branches with UltraFast Bootstrap supports (BS). (B) Maximum likelihood reduced plastome cladogram (36 Loliinae taxa, Podophorus included) constructed with IQTREE showing the relationships among the studied Fernandezian and Loliinae grasses. Oryza sativa was used to root the trees. Numbers indicate branches with UltraFast Bootstrap supports (BS). (C) Maximum likelihood nuclear rDNA cistron cladogram (35 Loliinae taxa, Podophorus excluded) constructed with IQTREE showing the relationships among the studied Fernandezian and Loliinae grasses. Oryza sativa was used to root the trees. Numbers indicate branches with UltraFast Bootstrap supports (BS). (D) Maximum likelihood nuclear ITS cladogram (36 Loliinae taxa, Podophorus included) constructed with IQTREE showing the relationships among the studied Fernandezian and Loliinae grasses. Oryza sativa was used to root the trees. Numbers indicate branches with UltraFast Bootstrap supports (BS).

FIGURE S2 | (A) Maximum likelihood nuclear TLF tree (135 Loliinae taxa) constructed with IQTREE showing the relationships among the studied Fernandezian and Loliinae grasses. Oryza sativa was used to root the trees. Numbers indicate branches with UltraFast Bootstrap supports (BS) $<100 \%$; the remaining branches have $100 \%$ BS values. (B) Maximum likelihood plastid ITS tree (135 Loliinae taxa) constructed with IQTREE showing the relationships among the studied Fernandezian and Loliinae grasses. Oryza sativa was used to root the trees. Numbers indicate branches with UltraFast Bootstrap supports (BS) <100\%; the remaining branches have 100\% BS values. (C) Maximum likelihood combined ITS-TLF tree (135 Loliinae taxa) constructed with IQTREE showing the relationships among the studied Fernandezian and Loliinae grasses. Oryza sativa was used to root the trees. Numbers indicate branches with UltraFast Bootstrap supports (BS).

FIGURE S3 | Fully expanded Bayesian maximum clade credibility dated chronogram of 135 Loliinae taxa constructed with BEAST2 using nuclear ITS and plastid TLF loci showing estimated nodal divergence times (medians, in Ma) and 95\% highest posterior density (HPD) intervals (bars) above branches and Posterior Probability Support (PPT) values below branches. Stars indicate secondary nodal calibration priors (means $\pm \mathrm{SD}$, in Mya) for the crown nodes of the BOP, Brachypodium + core pooids, and fine-leaved Loliinae clades.

TABLE S1 | List of taxa included in the phylogenetic study of the Fernandezian and other Loliinae grasses. Taxon, source, ploidy level, nuclear ITS, plastid trnTL and $\operatorname{trn} L F$, plastome and rDNA cistron Genbank codes, average alignment insert size, total number of pair-end reads, number of plastome assembled reads, and number of rDNA cistron assembled reads are indicated for the corresponding samples.

TABLE S2 | (A) Operational areas used in the stratified Loliinae DEC Lagrange analysis. (B) Dispersal rate matrices reflecting the palaeogeographic connectivity among the study areas in each historical scenario (time slices TSI, TSII, TSIII, TIV). (C) Operational areas used in the stratified American-Vulpia-Pampas DEC Lagrange analysis. (D) Dispersal rate matrices reflecting the palaeogeographic connectivity among the study areas in each historical scenario (time slices TSIII, TIV). 


\section{REFERENCES}

Baeza, C. M., Marticorena, C., Stuessy, T., Ruiz, E., and Negritto, M. (2007). Poaceae en el archipiélago de Juan Fernández (Robinson Crusoe). Gayana Bot. 64, 125-174.

Bernardello, G., Anderson, G. J., Stuessy, T. F., and Crawford, D. J. (2006). The angiosperm flora of the Archipelago Juan Fernandez (Chile): origin and dispersal. Can. J. Bot. 84, 1266-1281. doi: 10.1139/b06-092

Besnard, G., Christin, P.-A., Malé, P.-J. G., Lhuillier, E., Lauzeral, C., Coissac, E., et al. (2014). From museums to genomics: old herbarium specimens shed light on a C3 to C4 transition. J. Exp. Bot. 65, 6711-6721. doi: 10.1093/jxb/eru395

Bolger, A. M., Lohse, M., and Usadel, B. (2014). Trimmomatic: a flexible trimmer for Illumina sequence data. Bioinformatics 30, 2114-2120. doi: 10. 1093/bioinformatics/btu170

Bouckaert, R., Heled, J., Kühnert, D., Vaughan, T., Wu, C.-H., Xie, D., et al. (2014). BEAST 2: a software platform for Bayesian evolutionary analysis. PLoS Comput. Biol. 10:e1003537. doi: 10.1371/journal.pcbi.1003537

Capella-Gutiérrez, S., Silla-Martínez, J. M., and Gabaldón, T. (2009). trimAl: a tool for automated alignment trimming in large-scale phylogenetic analyses. Bioinformatics 25, 1972-1973. doi: 10.1093/bioinformatics/btp348

Carter, K. A., Liston, A., Bassil, N. V., Alice, L. A., Bushakra, J. M., Sutherland, B. L., et al. (2020). Target capture sequencing unravels Rubus evolution. Front. Plant Sci. 10:1615. doi: 10.3389/fpls.2019.01615

Catalan, P. (2006). "Phylogeny and evolution of Festuca L. and related genera of subtribe Loliinae (Poeae, Poaceae)," in Plant Genome: Biodiversity and Evolution, eds A. K. Sharma and A. Sharma (Enfield: Science Publishers), 255-303.

Catalan, P., and Müller, J. (2012). “Festuca L," in Flora de Argentina, Tomo II, Vol. 3, eds A. M. Anton and F. O. Zuloaga (Buenos Aires: Estudio Sigma S.R.L), 219-250.

Catalan, P., Torrecilla, P., López-Rodríguez, J. A., Müller, J., and Stace, C. A. (2007). A systematic approach to subtribe Loliinae (Poaceae: Pooideae) based on phylogenetic evidence. Aliso 23, 380-405. doi: 10.5642/aliso.20072301.31

Chernomor, O., Von Haeseler, A., and Minh, B. Q. (2016). Terrace aware data structure for phylogenomic inference from supermatrices. Syst. Biol. 65, 9971008. doi: 10.1093/sysbio/syw037

Connor, H. E. (1998). Festuca (Poeae: Gramineae) in New Zealand I. Indigenous taxa. N. Z. J. Bot. 36, 329-367. doi: 10.1080/0028825X.1998.9512574

Crisci, J., Freire-E, S., Sancho, G., and Katinas, L. (2001). Historical biogeography of the Asteraceae from Tandilia and Ventania mountain ranges (Buenos Aires, Argentina). Caldasia 23, 21-41.

Danton, P., and Perrier, C. (2017). Suppressions and additions to the flora of the Juan Fernández archipelago (Chile). Bot. Lett. 164, 351--360. doi: 10.1080/ 23818107.2017.1396249

Danton, P., Perrier, C., and de Reyes, G. M. (2006). Nouveau catalogue de la flore vasculaire de L'archipel Juan Fernández (Chili) Nuevo catálogo de la flora vascular del Archipiélago Juan Fernández (Chile). Acta Bot. Gallica 153, 399-587. doi: 10.1080/12538078.2006.10515559

Diaz-Perez, A., López-Álvarez, D., Sancho, R., and Catalan, P. (2018). Reconstructing the origins and the biogeography of species' genomes in the highly reticulate allopolyploid-rich model grass genus Brachypodium using minimum evolution, coalescence and maximum likelihood approaches. Mol. Phylogenet. Evol. 127, 256-271. doi: 10.1016/j.ympev.2018.06.003

Díaz-Pérez, A. J., Sharifi-Tehrani, M., Inda, L. A., and Catalan, P. (2014). Polyphyly, gene-duplication and extensive allopolyploidy framed the evolution of the ephemeral Vulpia grasses and other fine-leaved Loliinae (Poaceae). Mol. Phylogenet. Evol. 79, 92-105. doi: 10.1016/j.ympev.2014.06.009

Dierckxsens, N., Mardulyn, P., and Smits, G. (2017). NOVOPlasty: de novo assembly of organelle genomes from whole genome data. Nucleic Acids Res. 45:e18. doi: 10.1093/nar/gkw955

Dodsworth, S. (2015). Genome skimming for next-generation biodiversity analysis. Trends Plant Sci. 20, 525-527. doi: 10.1016/j.tplants.2015.06.012

Doyle, J. J., and Doyle, J. L. (1987). A rapid DNA isolation procedure for small quantities of fresh leaf tissue. Phytochem. Bull. 19, 11-15.

Dubcovsky, J., and Martínez, A. (1992). Distribución geográfica de los niveles de ploidía en Festuca. Parodiana 7, 91-99.

Greimler, J., López-Sepúlveda, P., and Reiter, K. (2017). “Chapter 6: vegetation,” in Plants of Oceanic Islands: Evolution, Biogeography, and Conservation of the
Flora of the Juan Fernández (Robinson Crusoe) Archipelago, eds T. Stuessy, D. Crawford, P. López-Sepúlveda, C. Baeza, and E. Ruiz (Cambridge: Cambridge University Press), 209-275.

Hackel, E. (1887). “Gramineae," in Die Natürlichen Pflanzefamilien, Vol. 2, eds A. Engler and K. Prantl (Leipzig: Verlag von Wilhelm Engelmann), 2-97.

Hand, M. L., Spangenberg, G. C., Forster, J. W., and Cogan, N. O. (2013). Plastome sequence determination and comparative analysis for members of the LoliumFestuca grass species complex. G3 3, 607-616. doi: 10.1534/g3.112.005264

Harrison, N., and Kidner, C. A. (2011). Next-generation sequencing and systematics: what can a billion base pairs of DNA sequence data do for you? Taxon 60, 1552-1566. doi: 10.1002/tax.606002

Inda, L. A., Sanmartín, I., Buerki, S., and Catalan, P. (2014). Mediterranean origin and miocene-holocene old world diversification of meadow fescues and ryegrasses (Festuca subgenus Schedonorus and Lolium). J. Biogeogr. 41, 600-614. doi: $10.1111 /$ jbi.12211

Inda, L. A., Segarra-Moragues, J. G., Müller, J., Peterson, P. M., and Catalan, P. (2008). Dated historical biogeography of the temperate Loliinae (Poaceae, Pooideae) grasses in the northern and southern hemispheres. Mol. Phylogenet. Evol. 46, 932-957. doi: 10.1016/j.ympev.2007.11.022

Juchniewicz, K. (1975). Flora kopalna Turowa koło Bogatyni w świetle analizy nabłonkowej. Pr. Muzeum Ziemi 24, 65-132.

Kalyaanamoorthy, S., Minh, B. Q., Wong, T. K., von Haeseler, A., and Jermiin, L. S. (2017). ModelFinder: fast model selection for accurate phylogenetic estimates. Nat. Methods 14, 587-589. doi: 10.1038/nmeth.4285

Katoh, K., and Standley, D. M. (2013). MAFFT multiple sequence alignment software version 7: improvements in performance and usability. Mol. Biol. Evol. 30, 772-780. doi: 10.1093/molbev/mst010

Kellogg, E. A. (2015). "Flowering plants. Monocots. Poaceae," in The Families and Genera of Vascular Plants, Vol. XIII, ed. K. Kubitzki (New York, NY: Springer), $1-408$.

Kergunteuil, A., Humair, L., Maire, A. L., Moreno-Aguilar, M. F., Godschalx, A., Catalan, P., et al. (2020). Tritrophic interactions follow phylogenetic escalation and climatic adaptation. Sci. Rep. 10:2074.

Larridon, I., Villaverde, T., Zuntini, A. R., Pokorny, L., Brewer, G. E., Epitawalage, N., et al. (2020). Tackling rapid radiations with targeted sequencing. Front. Plant Sci. 10:1655. doi: 10.3389/fpls.2019.01655

Leebens-Mack, J. H., Barker, M. S., Carpenter, E. J., Deyholos, M. K., Gitzendanner, M. A., Graham, S. W., et al. (2019). One thousand plant transcriptomes and the phylogenomics of green plants. Nature 574, 679-685. doi: 10.1038/s41586-0191693-2

Li, H.-T., Yi, T.-S., Gao, L.-M., Ma, P.-F., Zhang, T., Yang, J.-B., et al. (2019). Origin of angiosperms and the puzzle of the Jurassic gap. Nat. Plants 5, 461-470. doi: 10.1038/s41477-019-0421-0

Linder, H. P., Lehmann, C. E., Archibald, S., Osborne, C. P., and Richardson, D. M. (2018). Global grass (Poaceae) success underpinned by traits facilitating colonization, persistence and habitat transformation. Biol. Rev. Camb. Philos. Soc. 93, 1125-1144. doi: 10.1111/brv.12388

Malakasi, P., Bellot, S., Dee, R., and Grace, O. M. (2019). Museomics clarifies the classification of Aloidendron (Asphodelaceae), the iconic African tree aloes. Front. Plant Sci. 10:1227. doi: 10.3389/fpls.2019.01227

Minaya, M., Díaz-Pérez, A., Mason-Gamer, R., Pimentel, M., and Catalan, P. (2015). Evolution of the beta-amylase gene in the temperate grasses: nonpurifying selection, recombination, semiparalogy, homeology and phylogenetic signal. Mol. Phylogenet. Evol. 91, 68-85. doi: 10.1016/j.ympev.2015.05.014

Minaya, M., Hackel, J., Namaganda, M., Brochmann, C., Vorontsova, M. S., Besnard, G., et al. (2017). Contrasting dispersal histories of broad-and fineleaved temperate Loliinae grasses: range expansion, founder events, and the roles of distance and barriers. J. Biogeogr. 44, 1980-1993. doi: 10.1111/jbi.13012

Minh, B. Q., Nguyen, M. A. T., and von Haeseler, A. (2013). Ultrafast approximation for phylogenetic bootstrap. Mol. Biol. Evol. 30, 1188-1195. doi: 10.1093/molbev/mst024

Namaganda, M., Lye, K. A., Friebe, B., and Heun, M. (2006). AFLP-based differentiation of tropical African Festuca species compared to the European Festuca complex. Theor. Appl. Genet. 113, 1529-1538. doi: 10.1007/s00122006-0400-5

Nevill, P. G., Zhong, X., Tonti-Filippini, J., Byrne, M., Hislop, M., Thiele, K., et al. (2020). Large scale genome skimming from herbarium material for accurate plant identification and phylogenomics. Plant Methods 16, 1-8. 
Nguyen, L.-T., Schmidt, H. A., Von Haeseler, A., and Minh, B. Q. (2015). IQ-TREE: a fast and effective stochastic algorithm for estimating maximum-likelihood phylogenies. Mol. Biol. Evol. 32, 268-274. doi: 10.1093/molbev/msu300

Peña, C. M., Negritto, M. A., Ruiz, E., Baeza, C. M., and Finot, V. I. (2017). Revisión de Megalachne steud. (Poaceae: Pooideae: Poeae), género endémico del Archipiélago de Juan Fernández, Chile. Gayana Bot. 74, 189-199. doi: 10.4067/S0717-66432017005000216

Penneckamp-Furniel, D. (2018). Flora Vascular Silvestre del Archipiélago Juan Fernandez, 1st Edn. Valparaíso: Planeta de papel ediciones.

Penneckamp-Furniel, D. P., and Villegas, G. R. (2019). A new species of Megalachne (Poaceae) endemic to Alejandro Selkirk Island, Juan Fernandez Archipelago, Chile. Phytotaxa 418, 294-300. doi: 10.11646/phytotaxa.418.3.5

Ramos, V. A., Chemale, F., Naipauer, M., and Pazos, P. J. (2014). A provenance study of the Paleozoic Ventania System (Argentina): transient complex sources from Western and Eastern Gondwana. Gondwana Res. 26, 719-740. doi: 10. 1016/j.gr.2013.07.008

Ree, R. H., and Smith, S. A. (2008). Maximum likelihood inference of geographic range evolution by dispersal, local extinction, and cladogenesis. Syst. Biol. 57, 4-14. doi: 10.1080/10635150701883881

Richter, S., Schwarz, F., Hering, L., Böggemann, M., and Bleidorn, C. (2015). The utility of genome skimming for phylogenomic analyses as demonstrated for glycerid relationships (Annelida, Glyceridae). Genome Biol. Evol. 7, 3443-3462. doi: 10.1093/gbe/evv224

Saarela, J. M., Burke, S. V., Wysocki, W. P., Barrett, M. D., Clark, L. G., Craine, J. M., et al. (2018). A 250 plastome phylogeny of the grass family (Poaceae): topological support under different data partitions. PeerJ 6:e4299. doi: 10.7717/ peerj. 4299

Sancho, R., Cantalapiedra, C. P., López-Alvarez, D., Gordon, S. P., Vogel, J. P., Catalan, P., et al. (2018). Comparative plastome genomics and phylogenomics of Brachypodium: flowering time signatures, introgression and recombination in recently diverged ecotypes. New Phytol. 218, 1631-1644. doi: 10.1111/nph. 14926

Sanders, R. W., Stuessy, T. F., Marticorena, C., and Silva, O. (1987). Phytogeography and evolution of Dendroseris and Robinsonia, tree-Compositae of the Juan Fernandez Islands. Opera Bot. 92, 195-215.

Sanmartín, I. (2003). Dispersal vs. vicariance in the Mediterranean: historical biogeography of the Palearctic Pachydeminae (Coleoptera, Scarabaeoidea). J. Biogeogr. 30, 1883-1897. doi: 10.1046/j.0305-0270.2003.00982

Schneider, J., Winterfeld, G., Hoffmann, M. H., and Roeser, M. (2011). Duthieeae, a new tribe of grasses (Poaceae) identified among the early diverging lineages of subfamily Pooideae: molecular phylogenetics, morphological delineation, cytogenetics and biogeography. Syst. Biodivers. 9, 27-44. doi: 10.1080/14772000. 2010.544339

Schneider, J., Winterfeld, G., and Roeser, M. (2012). Polyphyly of the grass tribe Hainardieae (Poaceae: Pooideae): identification of its different lineages based on molecular phylogenetics, including morphological and cytogenetic characteristics. Org. Divers. Evol. 12, 113-132. doi: 10.1007/s13127-012-0077-3

Sebastian, P., Schaefer, H., and Renner, S. S. (2010). Darwin's Galapagos gourd: providing new insights 175 years after his visit. J. Biogeogr. 37, 975-978. doi: $10.1111 / j .1365-2699.2010 .02270$

Silva, C., Besnard, G., Piot, A., Razanatsoa, J., Oliveira, R. P., and Vorontsova, M. S. (2017). Museomics resolve the systematics of an endangered grass lineage endemic to north-western Madagascar. Ann. Bot. 119, 339--351. doi: 10.1093/ $\mathrm{aob} / \mathrm{mcw} 208$

Smarda, P., and Stancik, D. (2006). Ploidy level variability in South American fescues (Festuca L., Poaceae): use of flow cytometry in up to $51 / 2$-year-old caryopses and herbarium specimens. Plant Biol. 8, 73-80. doi: 10.1055/s-2005872821

Soltis, D. E., Moore, M. J., Sessa, E. B., Smith, S. A., and Soltis, P. S. (2018). Using and navigating the plant tree of life. Am. J. Bot. 105, 287-290. doi: 10.1002/ajb2. 1071

Soreng, R. J., Peterson, P. M., Davidse, G., Judziewicz, E. J., Zuloaga, F. O., Filgueiras, T. S., et al. (2003). Catalogue of new world grasses (Poaceae): IV. Subfamily Pooideae. Contr. U.S. Natl. Herb. 48, $1-730$.

Soreng, R. J., Peterson, P. M., Romaschenko, K., Davidse, G., Teisher, J. K., Clark, L. G., et al. (2017). A worldwide phylogenetic classification of the Poaceae (Gramineae) II: an update and a comparison of two 2015 classifications. J. Syst. Evol. 55, 259-290. doi: $10.1111 /$ jse.12262
Soreng, R. J., Peterson, P. M., Romaschenko, K., Davidse, G., Zuloaga, F. O., Judziewicz, E. J., et al. (2015). A worldwide phylogenetic classification of the Poaceae (Gramineae). J. Syst. Evol. 53, 117-137. doi: 10.1111/jse.12150

Spriggs, E. L., Eaton, D. A., Sweeney, P. W., Schlutius, C., Edwards, E. J., and Donoghue, M. J. (2019). Restriction-site-associated DNA sequencing reveals a cryptic Viburnum species on the North American coastal plain. Syst. Biol. 68, 187-203. doi: 10.1093/sysbio/syy084

Straub, S. C., Parks, M., Weitemier, K., Fishbein, M., Cronn, R. C., and Liston, A. (2012). Navigating the tip of the genomic iceberg: next-generation sequencing for plant systematics. Am. J. Bot. 99, 349-364. doi: 10.3732/ajb.1100335

Stuessy, T., Crawford, D., and Ruiz, E. (2017). "Chapter 13: patterns of phylogeny," in Plants of Oceanic Islands: Evolution, Biogeography, and Conservation of the Flora of the Juan Fernández (Robinson Crusoe) Archipelago, eds T. Stuessy, D. Crawford, P. López-Sepúlveda, C. Baeza, and E. Ruiz (Cambridge: Cambridge University Press), 209-275.

Stuessy, T. F., Foland, K. A., Sutter, J. F., Sanders, R. W., and Silva, M. (1984). Botanical and geological significance of potassium-argon dates from the Juan Fernandez Islands. Science 225, 49-51. doi: 10.1126/science.225.4657.49

Stuessy, T. F., Marticorena, C., Rodriguez, R., Crawford, D. J., and Silva, O. (1992). Endemism in the vascular flora of the Juan Fernández Islands. Aliso 13, 297-307. doi: 10.5642/aliso.19921302.03

Stuessy, T. F., Swenson, U., Crawford, D. J., Anderson, G., and Silva, O. (1998). Plant conservation in the Juan Fernandez archipelago, Chile. Aliso 16, 89-101. doi: 10.5642/aliso. 19971602.04

Tateoka, T. (1962). Starch grains of the endosperm in grass systematics. Bot. Mag. 75, 377-383. doi: 10.15281/jplantres1887.75.377

Tkach, N., Schneider, J., Döring, E., Wölk, A., Hochbach, A., Nissen, J., et al. (2020). Phylogeny, morphology and the role of hybridization as driving force of evolution in grass tribes Aveneae and Poeae (Poaceae). Taxon doi: 10.1002/ tax. 12204

Torrecilla, P., López-Rodríguez, J.-A., and Catalan, P. (2004). Phylogenetic relationships of Vulpia and related genera (Poeae, Poaceae) based on analysis of ITS and trnL-F sequences. Ann. Mo. Bot. Gard. 91, 124-158.

Triantis, K., Whittaker, R. J., Fernández-Palacios, J. M., and Geist, D. J. (2016). Oceanic archipelagos: a perspective on the geodynamics and biogeography of the World's. Front. Biogeogr. 8:29605. doi: 10.21425/F5FBG29605

Van de Paer, C., Hong-Wa, C., Jeziorski, C., and Besnard, G. (2016). Mitogenomics of Hesperelaea, an extinct genus of Oleaceae. Gene 594, 197-202. doi: 10.1016/j. gene.2016.09.007

Viruel, J., Conejero, M., Hidalgo, O., Pokorny, L., Powell, R. F., Forest, F., et al. (2019). A target capture-based method to estimate ploidy from herbarium specimens. Front. Plant Sci. 10:937. doi: 10.3389/fpls.2019.00937

Vogel, J. P., Garvin, D. F., Mockler, T. C., Schmutz, J., Rokhsar, D., Bevan, M. W., et al. (2010). Genome sequencing and analysis of the model grass Brachypodium distachyon. Nature 463, 763-768. doi: 10.1038/nature08747

Wakabayashi, J., and Sawyer, T. L. (2001). Stream incision, tectonics, uplift, and evolution of topography of the Sierra Nevada, California. J. Geol. 109, 539-562. doi: $10.1086 / 321962$

Welch, A. J., Collins, K., Ratan, A., Drautz-Moses, D. I., Schuster, S. C., and Lindqvist, C. (2016). The quest to resolve recent radiations: plastid phylogenomics of extinct and endangered Hawaiian endemic mints (Lamiaceae). Mol. Phylogenet. Evol. 99, 16-33. doi: 10.1016/j.ympev.2016. 02.024

Zedane, L., Hong-Wa, C., Murienne, J., Jeziorski, C., Baldwin, B. G., and Besnard, G. (2016). Museomics illuminate the history of an extinct, paleoendemic plant lineage (Hesperelaea, Oleaceae) known from an 1875 collection from Guadalupe Island, Mexico. Biol. J. Linn. Soc. 117, 44-57. doi: 10.1111/bij.12509

Conflict of Interest: The authors declare that the research was conducted in the absence of any commercial or financial relationships that could be construed as a potential conflict of interest.

Copyright $\odot 2020$ Moreno-Aguilar, Arnelas, Sánchez-Rodríguez, Viruel and Catalán. This is an open-access article distributed under the terms of the Creative Commons Attribution License (CC BY). The use, distribution or reproduction in other forums is permitted, provided the original author(s) and the copyright owner(s) are credited and that the original publication in this journal is cited, in accordance with accepted academic practice. No use, distribution or reproduction is permitted which does not comply with these terms. 